\title{
General Corrosion and Passive Film Stability
}

Chris Orme, Jeremy Gray, Joel Hayes, Lana Wong, Raul Rebak, Susan Carroll, Jennifer Harper, Greg Gdowski

July 20, 2005 
This document was prepared as an account of work sponsored by an agency of the United States Government. Neither the United States Government nor the University of California nor any of their employees, makes any warranty, express or implied, or assumes any legal liability or responsibility for the accuracy, completeness, or usefulness of any information, apparatus, product, or process disclosed, or represents that its use would not infringe privately owned rights. Reference herein to any specific commercial product, process, or service by trade name, trademark, manufacturer, or otherwise, does not necessarily constitute or imply its endorsement, recommendation, or favoring by the United States Government or the University of California. The views and opinions of authors expressed herein do not necessarily state or reflect those of the United States Government or the University of California, and shall not be used for advertising or product endorsement purposes.

This work was performed under the auspices of the U.S. Department of Energy by University of California, Lawrence Livermore National Laboratory under Contract W-7405-Eng-48. 


\section{CONTENTS}

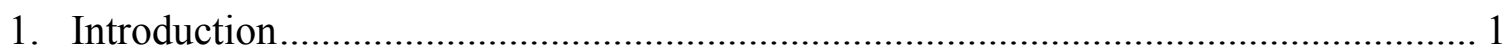

2. General Corrosion of Alloy 22 from 60 to $220^{\circ} \mathrm{C}$............................................... 1

3. General Corrosion from Weight loss ................................................................... 2

3.1. Alloy 22 and Titanium: Long-Term Corrosion Tests at 60 and $90^{\circ} \mathrm{C} \mathrm{\ldots ..............} 2$

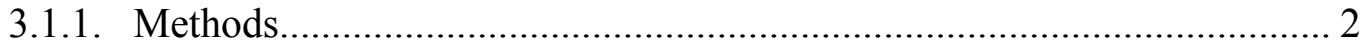

3.1.2. Results and Discussion ........................................................................ 3

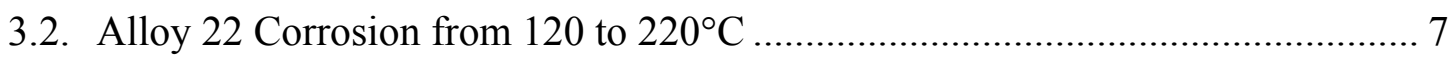

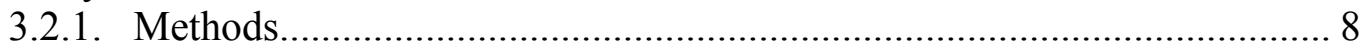

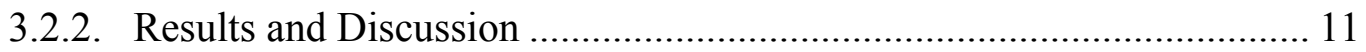

3.2.3. Implications to the General Corrosion Model ................................... 24

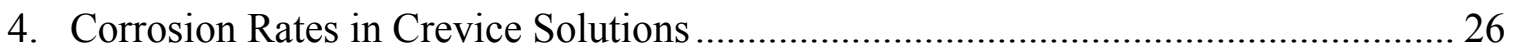

4.1. Connection to Crevice Corrosion Models........................................................ 27

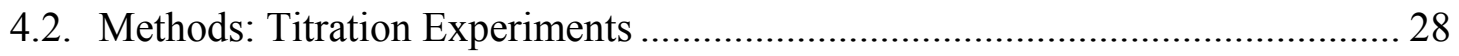

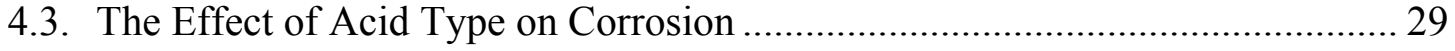

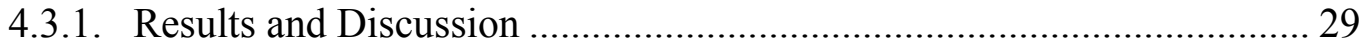

4.4. The Corrosion-Inhibiting Effects of Nitrate and Sulfate on Alloy 22 in Acidic

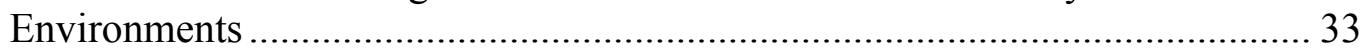

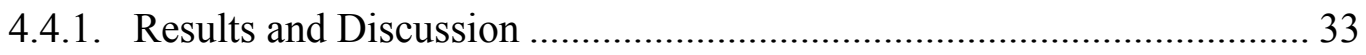

4.5. Implications to Alloy 22 Corrosion at Yucca Mountain.................................. 39

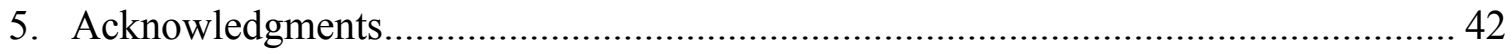

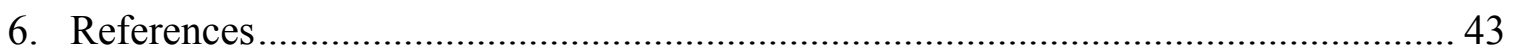

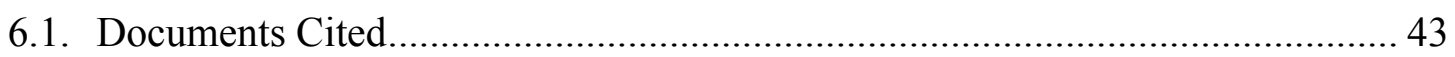

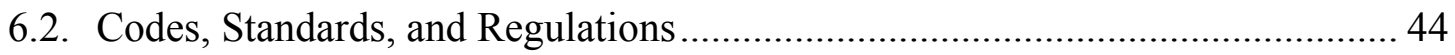

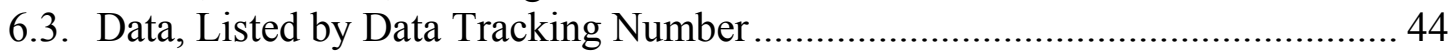




\section{Introduction}

This report summarizes both general corrosion of Alloy 22 from 60 to $220^{\circ} \mathrm{C}$ and the stability of the passive (oxide) film from 60 to $90^{\circ} \mathrm{C}$ over a range of solution compositions that are relevant to the in-drift chemical environment at the waste package surface. The general corrosion rates were determined by weight-loss measurements in a range of complex solution compositions representing the products of both the evaporation of seepage water and also the deliquescence of dust previously deposited on the waste canisters. These data represent the first weight-loss measurements performed by the program at temperatures above $90^{\circ} \mathrm{C}$. The low corrosion rates of Alloy 22 are attributed to the protective oxide film that forms at the metal surface. In this report, changes in the oxide film composition are correlated with weight loss at the higher temperatures (140$220^{\circ} \mathrm{C}$ ) where film characterization had not been previously performed. The stability of the oxide film was further analyzed by conducting a series of electrochemical tests in progressively more acidic solutions to measure the general corrosion rates in solutions that mimic crevice or pit environments.

\section{General Corrosion of Alloy 22 from 60 to $220^{\circ} \mathrm{C}$}

The model for the general corrosion rate of Alloy 22 in the Yucca Mountain Repository Safety Analysis Report (BSC, 2004a) is dependent on temperature but independent of solution composition. The rate expression combines long-term data derived from weight-loss experiments conducted in the LLNL Long Term Corrosion Test Facility (LTCTF) with data from a second study based utilizing short-term electrochemical tests. The two independent studies yielded contradictory results for temperature dependence. The long-term weight-loss measurements show no temperature dependence, while the short-term electrochemical rates did exhibit such dependence. The absence of temperature dependence in the long-term rates may be an artifact of the limited temperature range of the associated tests (conducted at 60 and $90^{\circ} \mathrm{C}$ ), the formation of carbonate and silica scales on test coupons from the complex test solutions, and high uncertainty in the weight-loss measurements. The inability to describe general corrosion rates as a function of solution composition may be an artifact of the limited number of and complexity of test solutions. Both the long-term weight loss and the shortterm electrochemical experiments were conducted in modified sodium carbonate-type waters, in which important factors believed to inhibit localized corrosion such as the $\mathrm{NO}_{3} / \mathrm{Cl}$ ratio are the same in all three solutions.

We conducted a series of autoclave experiments from 120 to $220^{\circ} \mathrm{C}$ with $\mathrm{NO}_{3} / \mathrm{Cl}$ from 0.05 to 6.7 to obtain a more accurate representation of the dependence of general Alloy 22 corrosion on both temperature and solution composition. In this study, weightloss measurements were complemented by an array of surface analyses to measure the chemical composition, homogeneity, and thickness of the oxide layers, so as to yield a better understanding of the relationship between passive film stability and net corrosion rate in these environments. These environments are important to the Yucca Mountain safety case because recent dust deliquescence studies show that brines with high nitrate 
concentrations are likely to be stable on waste package surfaces at temperatures well above $150^{\circ} \mathrm{C}$ (Carroll et al., 2005).

Prior to reviewing the new general corrosion rate data from the autoclave and titration experiments, we review the Alloy 22 and Ti corrosion results from the LLNL Long Term Corrosion Test Facility that form the basis of general corrosion model (BSC, 2004a, b).

\section{General Corrosion from Weight loss}

\subsection{Alloy 22 and Titanium: Long-Term Corrosion Tests at 60 and $90^{\circ} \mathrm{C}$}

General corrosion rates of Alloy 22 and Ti (grades 7, 12, and 16) were determined from weight-loss measurements of samples that had been reacted with modified carbonate solutions over a 5-year period in the Long-Term Corrosion Test Facility at 60 and $90^{\circ} \mathrm{C}$. Details of these experiments are available in Wong et al. (2003a, b, c) and in DTN LL030412512251.057.

\subsubsection{Methods}

The corrosion rates of Alloy 22 and Ti (grades 7, 12, and 16) were determined using the ASTM G31 procedure for laboratory coupon immersion corrosion testing and the ASTM G1 procedure for coupon preparation, cleaning and evaluation. Testing vessels of 2000 liter capacity were used. Each was filled with about 1000 liters of a test solution and naturally aerated by allowing ambient air to circulate above the test solution. Three test solutions were used: SDW (Simulated Dilute Water), SCW (Simulated Concentrated Water), and SAW (Simulated Acidic Water). The compositions of these solutions are described below in Section 3.1.2.1. About half of the sample coupons were exposed only to the liquid phase in the test vessel (complete immersion), and the other half were exposed to the vapor phase (i.e., they were suspended over the liquid surface). The coupons were exposed to the test environments at their free corrosion potential ( $\left.E_{\text {corr }}\right)$. Each coupon was electrically isolated from the other coupons. The reported test temperature corresponded to the liquid phase temperature. The exposure time for each coupon was approximately 5 years. Energy dispersive spectroscopy (EDS) and x-ray photoelectron spectroscopy (XPS) were performed on select coupons.

After a 5-year exposure to each test solution, all 134 Alloy 22 and all $382 \mathrm{Ti}$ coupons were removed from their test vessels, rinsed with deionized (DI) water, and stored in individual pre-labeled containers. All coupons were then weighed three times at different times of the day to ensure complete removal of moisture. The coupons were cleaned of mineral deposits prior to final weighing, and the resulting data were used to calculate the long-term corrosion rates. The cleaned surfaces were deposit-free. They showed no noticeable evidence of corrosion having occurred during the tests. All coupons tested in alkaline solutions (SCW and SDW) were cleaned per ASTM G1-C6.1, which specifies cleaning with an $\mathrm{HCl}$ solution at ambient temperature. All coupons tested in acidic solution (SAW) were cleaned per ASTM G1-C6.1 and C7.4, in which coupons were immersed in an $\mathrm{HCl}$ solution, rinsed in DI water, immersed in hot $\left(90-95^{\circ} \mathrm{C}\right)$ sodium hydroxide and potassium permanganate $\left(\mathrm{NaOH} / \mathrm{KMnO}_{4}\right)$, and cleaned with 
diammonium citrate $\left(\left(\mathrm{NH}_{4}\right)_{2} \mathrm{HC}_{6} \mathrm{H}_{5} \mathrm{O}_{7}\right)$ solution at ambient temperature. The corrosion rates $(\mathrm{CR})$ of the cleaned coupons were then calculated using Equation 1:

$$
\mathrm{CR}(\mathrm{nm} / \text { year })=\left(8.76 \times 10^{10}\right) \Delta W /(\delta A t)
$$

where $8.76 \times 10^{10}$ is a proportionality constant that accommodates unit conversions for length and time, $\Delta W$ is the mass loss in grams after 5+ years, $\delta$ is the density (Alloy $22=$ $8.69 \mathrm{~g} / \mathrm{cm}^{3}$; Ti alloys $\left.=4.52 \mathrm{~g} / \mathrm{cm}^{3}\right), A$ is the exposed surface area of each coupon $\left(\mathrm{cm}^{2}\right)$, and $t$ is the exposure time (hours). Corrosion rates for samples with artificial crevices were calculated as equivalent general corrosion using Equation 1, because no localized corrosion was observed. Thus, results from samples labeled "crevice coupons" in fact represent general corrosion only.

\subsubsection{Results and Discussion}

\subsubsection{Alloy 22}

Figures 1 and 2 plot weight-loss corrosion rates for the Alloy 22 coupons exposed to the SAW, SCW, and SDW solutions at $60^{\circ} \mathrm{C}$ and $90^{\circ} \mathrm{C}$ for over 5 years. Corrosion rates were similar for specimens reacted in different waters showing no temperature dependence. The individual corrosion rates for the weight-loss coupons generally fall in the range $0-25 \mathrm{~nm} /$ year (ignoring negative outliers and some statistically insignificant positive outliers). These results are largely consistent with $20-\mathrm{nm} / \mathrm{year}$ weight-loss corrosion rates calculated for these waters after 2 years of reaction (Farmer et al., 2000). Stereomicroscopic and scanning electron microscope (SEM) observations of reacted specimens indicated little or no corrosion for Alloy 22; machining grooves remained uniform and sharp throughout each coupon. The averaged corrosion rate data from the $60^{\circ} \mathrm{C}$ experiments are used as input to the general corrosion model (BSC, 2004a, b) in the form of the temperature-independent rate constant. These results were then coupled with the temperature dependence observed in short-term electrochemical systems in SAW test solution to build the general corrosion rate model.

The modified carbonate waters were based on J-13 well water composition (Harrar et al., 1990), which was considered representative of the pore waters that would seep through the rock formations above the repository and onto the waste canisters. This study used three modifications of the well water to represent various extents of evaporation and acid conditions on the waste package. Two waters have $\mathrm{pH}\left(25^{\circ} \mathrm{C}\right) \approx 10$ and are 10 times (SDW) and 1000 times (SCW) more concentrated than the J-13 well water. The third water represents a concentrated acid water (SAW), in which sulfuric, hydrochloric, and/or nitric acid replace dissolved carbonate and lower the $\mathrm{pH} \approx 3\left(25^{\circ} \mathrm{C}\right)$. Table 1 shows the measured major chemistry in these brines sampled at the 5-year period. Although $\mathrm{NO}_{3}$ and $\mathrm{Cl}$ concentrations in these solutions are varied by 400 times and solution $\mathrm{pH}$ is acid or alkaline, the $\mathrm{NO}_{3} / \mathrm{Cl}$ is approximately 0.5 for most of the test solutions. It is possible that at such a high $\mathrm{NO}_{3} / \mathrm{Cl}$ ratio, the $\mathrm{NO}_{3}$ inhibits both local and general corrosion. It is also possible that the scale present on metal coupons served to protect the Alloy 22 surfaces from the solutions and thereby limits corrosion. 
Table 1. Measured composition of corrosion solution after 5 years of reaction with test specimens in the LLNL Long Term Corrosion Test Facility.

\begin{tabular}{|c|c|c|c|c|c|c|c|c|c|c|c|c|c|}
\hline \multirow[b]{2}{*}{ Sample ID } & \multirow{2}{*}{$\begin{array}{c}\text { Solution } \\
\text { Type* }^{*}\end{array}$} & \multirow{2}{*}{$\begin{array}{l}\mathrm{pH} \text { at } \\
25^{\circ} \mathrm{C}\end{array}$} & \multicolumn{11}{|c|}{ Chemical Composition, molal } \\
\hline & & & $\mathrm{Ca}$ & $\mathrm{Mg}$ & $\mathrm{Na}$ & Si & $\mathbf{K}$ & TIC & $\mathbf{F}$ & $\mathrm{Cl}$ & $\mathrm{NO}_{3}$ & $\mathrm{SO}_{4}$ & $\mathrm{NO}_{3} / \mathrm{Cl}$ \\
\hline 13-072904 & SDW & 9.58 & 0.00003 & ND & 0.02 & 0.0004 & 0.001 & 0.011 & 0.0007 & 0.002 & 0.001 & 0.002 & 0.53 \\
\hline 14-072904 & SDW & 10.19 & 0.00003 & ND & 0.02 & 0.0015 & 0.001 & 0.004 & 0.0007 & 0.003 & 0.001 & 0.002 & 0.36 \\
\hline 17-072904 & SDW & 9.59 & ND & ND & 0.01 & 0.0002 & 0.001 & 0.010 & 0.0006 & 0.002 & 0.012 & 0.002 & 7.39 \\
\hline 22-072904 & SDW & 8.70 & 0.003 & 0.00005 & 0.02 & 0.0005 & 0.001 & 0.001 & ND & 0.003 & 0.004 & 0.002 & 1.31 \\
\hline 23-072904 & SDW & 9.50 & 0.00003 & ND & 0.02 & 0.0001 & 0.001 & 0.010 & 0.0006 & 0.002 & 0.001 & 0.002 & 0.64 \\
\hline $24-072904$ & SDW & 10.15 & ND & ND & 0.02 & 0.0008 & 0.001 & 0.003 & 0.0016 & 0.003 & 0.001 & 0.002 & 0.19 \\
\hline $29-072904$ & SDW & 9.64 & ND & ND & 0.02 & 0.0002 & 0.001 & 0.009 & 0.0008 & 0.003 & 0.002 & 0.003 & 0.48 \\
\hline 30-072904 & SDW & 8.37 & 0.001 & 0.001 & 0.02 & ND & 0.098 & 0.0002 & ND & 0.003 & 0.0001 & 0.002 & 0.03 \\
\hline 09-072904 & SCW & 10.14 & 0.00004 & ND & 1.43 & 0.0018 & 0.076 & 0.686 & 0.069 & 0.196 & 0.110 & 0.129 & 0.56 \\
\hline $10-072904$ & SCW & 10.62 & 0.00006 & ND & 1.51 & 0.0006 & 0.091 & 0.586 & 0.076 & 0.188 & 0.106 & 0.123 & 0.57 \\
\hline 11-072904 & SCW & 10.12 & 0.00005 & ND & 1.46 & 0.0015 & 0.091 & 0.611 & 0.067 & 0.191 & 0.106 & 0.123 & 0.55 \\
\hline $12-072904$ & SCW & 10.68 & 0.00006 & ND & 1.47 & 0.0006 & 0.090 & 0.551 & 0.080 & 0.195 & 0.108 & 0.128 & 0.56 \\
\hline 20-072904 & SCW & 10.59 & 0.00007 & ND & 1.73 & 0.0019 & 0.091 & 0.659 & 0.070 & 0.200 & 0.113 & 0.131 & 0.56 \\
\hline 21-072904 & SCW & 10.19 & 0.00003 & 0.00008 & 1.72 & 0.0002 & 0.091 & 0.588 & 0.032 & 0.205 & 0.101 & 0.191 & 0.49 \\
\hline $27-072904$ & SCW & 10.33 & 0.00007 & ND & 1.81 & 0.0018 & 0.092 & 0.630 & 0.064 & 0.199 & 0.116 & 0.129 & 0.58 \\
\hline $28-072904$ & SCW & 10.76 & 0.00006 & ND & 1.83 & 0.0038 & 0.092 & 0.511 & 0.074 & 0.211 & 0.119 & 0.138 & 0.56 \\
\hline $25-072904$ & SAW & 2.77 & 0.002 & 0.002 & 1.97 & 0.0011 & 0.102 & 0.000016 & 0.002 & 0.004 & 0.001 & 0.002 & 0.19 \\
\hline 26-072904 & SAW & 3.88 & 0.002 & 0.002 & 1.95 & 0.0025 & 0.097 & 0.000005 & ND & 0.809 & 0.423 & 0.470 & 0.52 \\
\hline
\end{tabular}

*SDW is Simulated Dilute Water, SCW is Simulated Concentrated Water, and SAW is Simulated Acidic Water.

Source: DTN LL041100112251.124. 


\section{Corrosion Rate for 5+ Year LTCTF Samples - Alloy 22 Weight Loss Coupons}

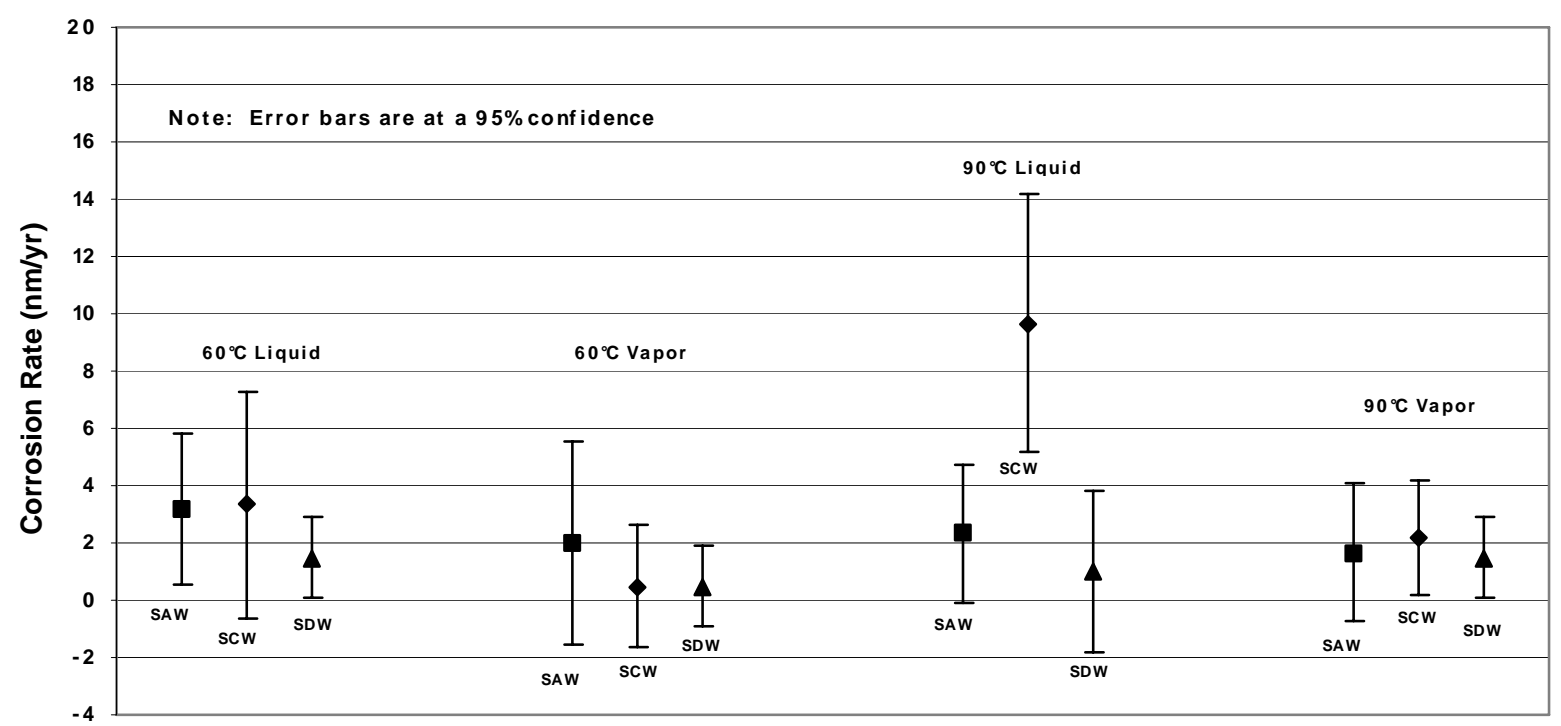

Figure 1. Corrosion rates for Alloy 22 weight-loss coupons in SAW, SCW, and SDW.

\section{Corrosion Rate for 5+ Year LTCTF Samples - Alloy 22 Crevice Coupons}

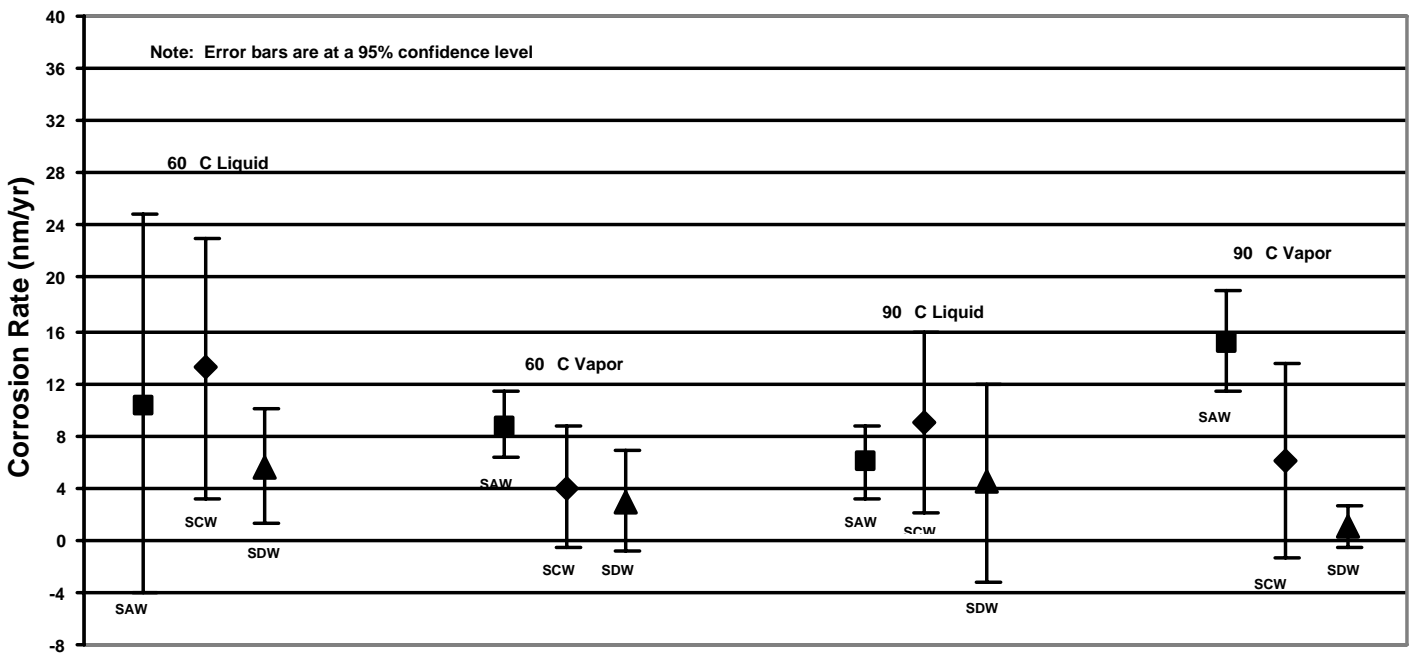

Figure 2. Corrosion rates for Alloy 22 crevice coupons in SAW, SCW, and SDW. These rates reflect general corrosion rates determined by weight loss because no local corrosion was observed. 


\subsubsection{Ti grades 7,12 , and 16}

In this section, we briefly summarize general corrosion rates for Ti grades 7, 12, and 16 in SDW, SCW, and SAW solutions for a 2- to 5-year period. Titanium grade 7 is the current alloy designated for drip shields to be emplaced above the waste packages. Figure 3 shows that Ti corrosion rates are dependent both on alloy grade and on temperature, where Ti grade 7 rates are slower than Ti grade 16 rates, which are slower than Ti grade 12 rates. Rates for fully immersed coupons are about 5 to 10 times greater than those for coupons in the vapor phase. In contrast to the Alloy 22 corrosion rates, which exhibited no temperature dependence, the titanium corrosion rates showed significant temperature dependence. This would indicate that scale precipitation did not effectively isolate the metal surface from the solution in the titanium tests (and may imply the same for the Alloy 22 tests as there is relatively little corrosion of either type of metal, suggesting the same type and degree of scale precipitation). For the three grades of titanium tested, the rates are roughly 3-4 times higher at $90^{\circ} \mathrm{C}$ than at $60^{\circ} \mathrm{C}$. Grade 7 rates increase from 8 to $31 \mathrm{~nm} /$ year, grade 16 rates increase from 17 to $70 \mathrm{~nm} /$ year, and grade 12 rates increase from 71 to $201 \mathrm{~nm} /$ year.

Corrosion rates for titanium also appear to be dependent on fluoride concentration, based on the 5- to 10-fold higher corrosion rates observed in SCW solutions than in SDW and SAW solutions (Figure 4). Fluoride concentrations in SCW are 100 times higher than in SDW and SAW. Ionic strength and $\mathrm{pH}$ cannot explain the differences, because SCW and SDW have similar $\mathrm{pH}$ but very different corrosion rates. Similarly, SAW and SCW have similar ionic strength but very different corrosion rates.

Corrosion Rate for Titanium Grades 7, 16 and 12 in a SCW Solution

Crevice Coupons

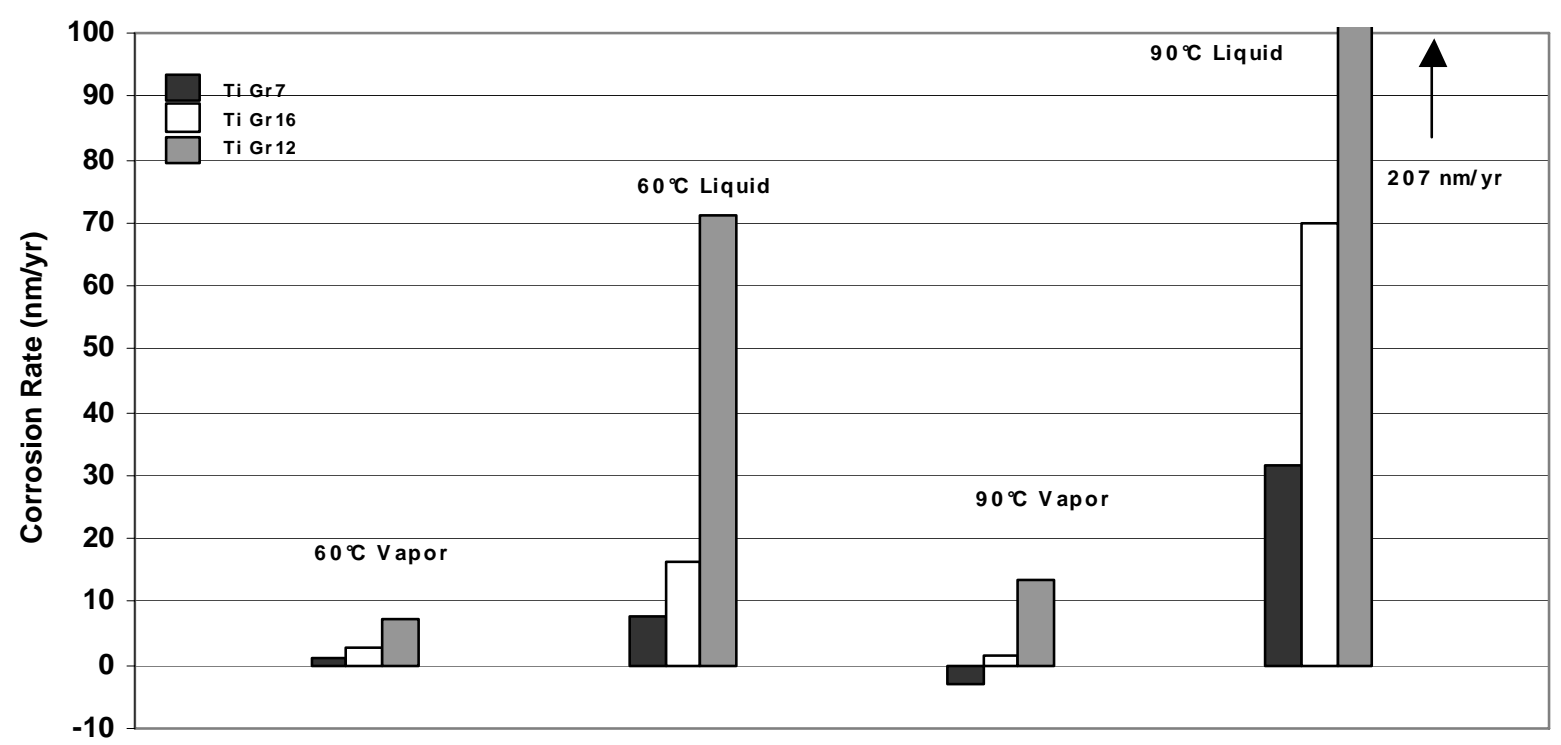

Figure 3. The effect of alloy composition on the corrosion rate of titanium alloys for crevice coupons immersed in a concentrated alkaline solution (SCW). 
Corrosion Rate for Titanium Grade 12

Weight Loss Coupons

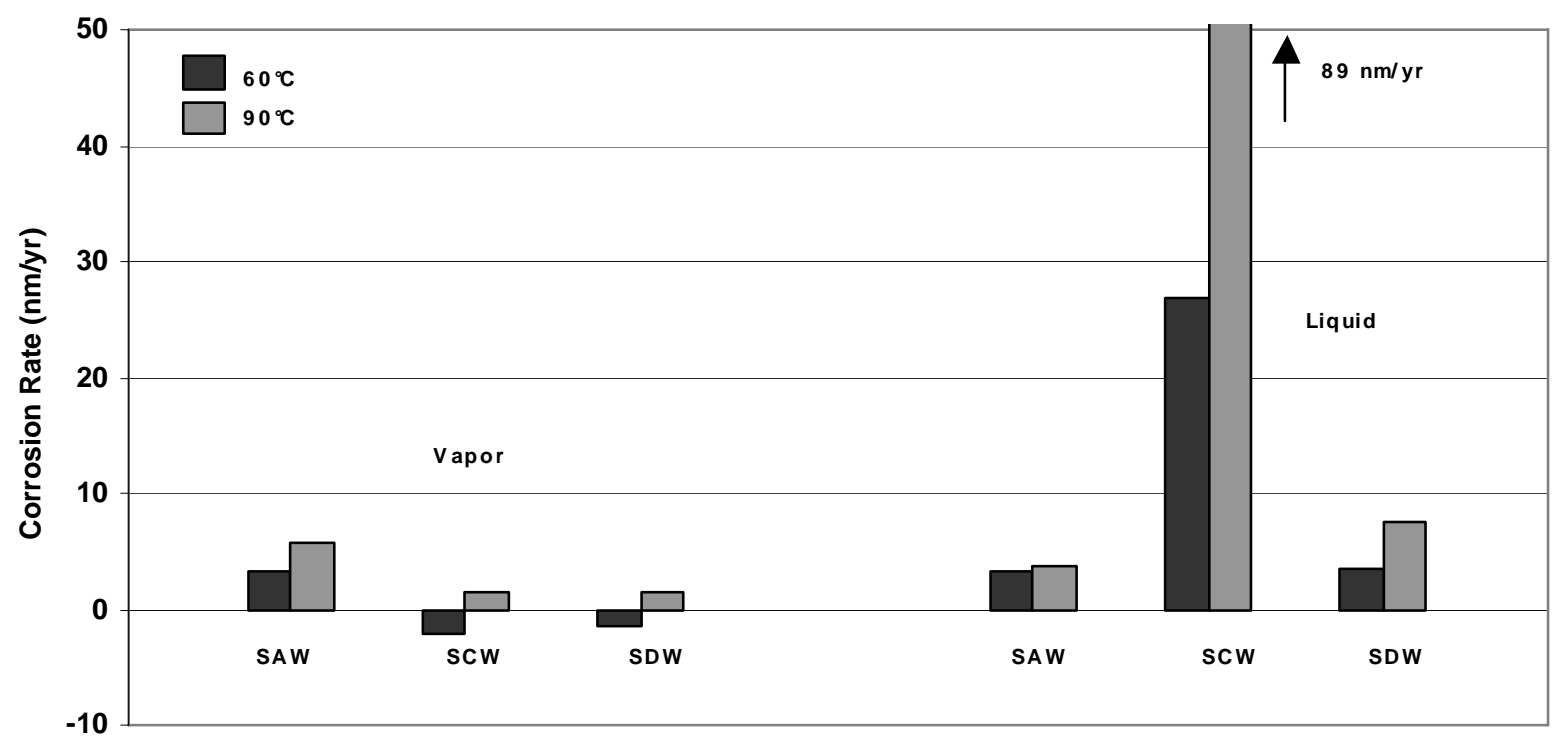

Figure 4. The effect of temperature and solution composition on the corrosion rate of titanium grade 12 in aqueous solution and in overlying vapor.

\subsection{Alloy 22 Corrosion from 120 to $220^{\circ} \mathrm{C}$}

The newer autoclave experiments fill a very important testing role for Yucca Mountain Project, because they can be used to evaluate the performance of Alloy 22 in concentrated brines at temperatures above $120^{\circ} \mathrm{C}$. Very little prior corrosion data exist for temperatures above $120^{\circ} \mathrm{C}$, and those data that have been previously collected are from electrochemical measurements only. Weight-loss measurements are a more accurate reflection of long-term corrosion, reflecting both natural oxide evolution and also the formation of both anodic and cathodic regions on the alloy surface (a phenomenon which serves to decrease the general corrosion rate). Autoclaves not only allow weight-loss studies to be conducted at elevated temperatures, but a properly designed experiment allows results to be obtained in as little as three months.

The objective of these experiments is to examine the influence of temperature and the nitrate to chloride ratio on the corrosion rate of Alloy 22. These weight-loss experiments differ from the Long Term Corrosion Test Facility experiments in three important ways. Firstly, the experiments are conducted over a much wider and higher temperature range. We anticipate that net corrosion rates at these higher temperatures will be above the detection limit of the weight-loss technique such that a general corrosion model can be established from weight-loss data alone. Secondly, the experiments are conducted in simple $\mathrm{NaCl}-\mathrm{NaNO}_{3}-\mathrm{KNO}_{3}$ solutions, in contrast to the complex modified carbonate waters used in the Long Term Corrosion Test Facility 5-year experiments. 
Therefore, no carbonate or silica scale will form on the coupons. Thirdly, the solution $\mathrm{NO}_{3} / \mathrm{Cl}$ ratio is varied from 0.05 to 6.7 , in order to examine the influence of the nitrate/chloride ratio on the corrosion rate. In particular, the range of this ratio extends below and above 0.2 , a value which is sufficiently high to inhibit crevice corrosion in electrochemical tests. The absolute concentrations and $\mathrm{NO}_{3} / \mathrm{Cl}$ ratio represent a range of solution compositions that might form at the waste package surface due to the evaporation of seepage water or by the deliquescence of salts, as might be included in dust deposited on the packages during pre-closure ventilation.

\subsubsection{Methods}

\subsubsection{Autoclave Capabilities}

The autoclave facilities at LLNL include three units made of Hastelloy C-276, which is composed of the same elements as Alloy 22 (Figure 5a). This prevents the introduction of "foreign" components from corrosion of the canister walls. Also, due to the high corrosion resistance of C-276, there is minimal introduction of any components associated with reaction of test solutions with the canister walls. A special sample holder (Figure $5 \mathrm{~b}$ ) was designed and fabricated out of Alloy 22, both to prevent contamination of the system and to eliminate any galvanic coupling between sample and holder. These sample holders hold foil weight-loss samples as well as polished Alloy 22 pucks, which are used for surface analysis by atomic force microscopy (AFM), transmission electron microscopy (TEM), Auger electron spectroscopy, and XPS. All of the samples are held vertically to prevent any precipitated material from settling on the surface. The facility also includes eight Teflon acid digestion bombs, capable of reaching temperatures of $175^{\circ} \mathrm{C}$ with the samples held in an inert vessel (Figure 5c). Special Teflon sample holders were designed to hold the metal samples.
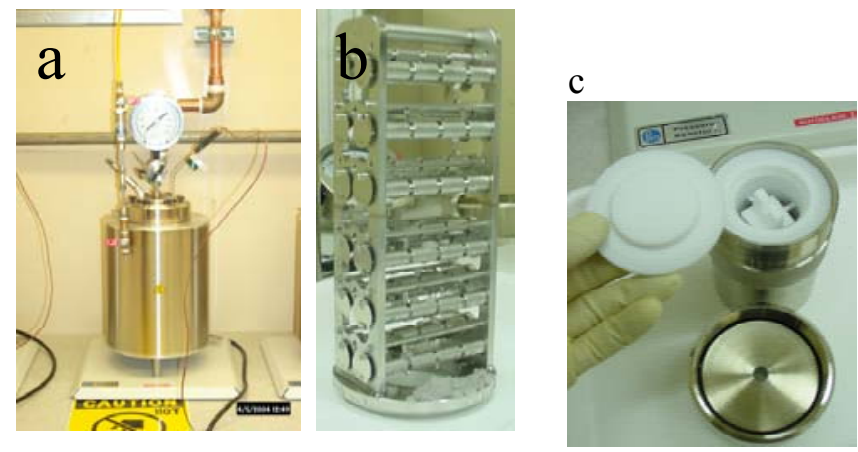

Figure 5. (a) Autoclave setup, (b) Alloy 22 sample holder for autoclave setup, and (c) Teflon acid digestion bomb with Teflon sample holder inside. 


\subsubsection{Environments}

The solutions were high ionic strength brines containing $\mathrm{Na}^{+}, \mathrm{Cl}^{-}, \mathrm{K}^{+}$, and $\mathrm{NO}_{3}{ }^{-}$. The environments were designed to span the range of $\mathrm{NO}_{3} / \mathrm{Cl}$ ratios in which crevice corrosion has been shown to initiate at $110^{\circ} \mathrm{C}$. For practical reasons, the concentrations were chosen such that all dissolved salts were undersaturated with respect to the solid salts at $90^{\circ} \mathrm{C}$, allowing the fully mixed solutions to be poured into the autoclaves. The solution IDs and the salt concentrations are shown in Table 2.

Table 2. Test solutions used in autoclaves and Teflon bombs

\begin{tabular}{|l|l|l|l|l|l|}
\hline Solution ID & $\begin{array}{c}\mathrm{NaCl} \\
(\mathbf{m})\end{array}$ & $\begin{array}{c}\mathrm{NaNO}_{3} \\
(\mathbf{m})\end{array}$ & $\begin{array}{c}\mathrm{KNO}_{3} \\
(\mathbf{m})\end{array}$ & {$\left[\mathrm{NO}_{3}{ }^{-}\right] /\left[\mathrm{Cl}^{-}\right]$} & $\begin{array}{l}\text { Total } \\
\text { Molal }\end{array}$ \\
\hline 1 & 6.4 & - & 2.0 & 0.3125 & 8.4 \\
\hline 2 & 2.7 & 3.4 & 15.1 & 6.7 & 21.2 \\
\hline 3 & 6.4 & - & 0.3 & 0.05 & 6.7 \\
\hline 4 & 6.4 & - & 3.2 & 0.5 & 9.6 \\
\hline
\end{tabular}

\subsubsection{Weight-Loss Measurements}

A set of experiments has been performed at time intervals of 4 months and 9 months to examine the influence of temperature and nitrate/chloride ratio on the corrosion rate of Alloy 22. The details of the test conditions are shown in Table 3. Weight-loss measurements were made in the environments marked as " $4 \mathrm{~m}$ " or " $9 \mathrm{~m}$ " at $\sim 4$ months and 9 months, respectively. The Teflon bombs held fewer samples than the Hastelloy autoclaves. Once a Teflon bomb was opened, all samples were removed. The larger volume of the Hastelloy autoclaves allowed the use of sufficient samples to support removal at two different times. The environments marked as "P" are experiments that are currently being initiated, and they will contain both weight-loss samples, polished pucks for oxide layer characterization, and foil crevice corrosion specimens to examine the influence of temperature and nitrate/chloride ratio on crevicing of Alloy 22. The foil crevice corrosion samples are a new invention. They will simultaneously address the question of whether or not crevice corrosion will occur spontaneously in these environments and provide a direct measure of the difference in corrosion rate (as measured by weight loss) for general and crevice corrosion under more realistic conditions (where the process is not being driven by imposed electrochemical forces). The foil weights were measured three times: before they were introduced into the autoclave, immediately after removal from the autoclaves (after rinsing briefly with Millipore water to remove excess salts precipitating as the solution dried), and after a more extensive cleaning designed to remove the oxide (using procedures within ASTMG1-03 C6.1). The cleaning method was developed and tested to clean the weight-loss specimens in the LTCTF (see Section 3.1). The samples were cleaned in two solutions: $150 \mathrm{ml}$ of $37 \% \mathrm{HCl}: 1000 \mathrm{ml} \mathrm{H}_{2} \mathrm{O}$ and $100 \mathrm{ml} \mathrm{H}_{2} \mathrm{SO}_{4}: 1000 \mathrm{ml} \mathrm{H}_{2} \mathrm{O}$. After the samples 
Table 3. Conditions for completed general corrosion tests

\begin{tabular}{|l|l|l|l|l|l|}
\hline \multicolumn{2}{|c|}{ Solution } & \multicolumn{5}{c|}{ Temperature $^{\circ} \mathbf{C}$} \\
\hline $\mathbf{N O}_{3}{ }^{-}{ }^{\prime} \mathbf{C l}^{-}$ & Total Molal & $\mathbf{1 2 0}$ & $\mathbf{1 4 0}$ & $\mathbf{1 6 0}$ & $\mathbf{2 2 0}$ \\
\hline 0.05 & 6.7 & & $4 \mathrm{~m}, 9 \mathrm{~m}$ & & \\
\hline 0.3125 & 8.4 & $4 \mathrm{~m}$ & $4 \mathrm{~m}$ & $4 \mathrm{~m}$ & $4 \mathrm{~m}, 9 \mathrm{~m}$ \\
\hline 0.5 & 9.6 & & $4 \mathrm{~m}, 9 \mathrm{~m}$ & & $\mathrm{P}$ \\
\hline 6.7 & 21.2 & $4 \mathrm{~m}$ & $4 \mathrm{~m}$ & $4 \mathrm{~m}, \mathrm{P}$ & $\mathrm{P}$ \\
\hline
\end{tabular}

${ }^{1}$ Entries indicate approximate duration of aging, 4 months or 9 months.

${ }^{2}$ Proposed experiments are marked as "P" and will include crevice specimens.

Source: LL040502512251.099 and LL040907112251.122.

were ultrasonically cleaned in the solutions for 3 minutes, they were rinsed with Millipore water (Hayes, 2004a). The weight loss is the difference between the final weight after the cleaning procedure and the initial weight. The corrosion rate is determined from the weight-loss and the area of the specimen. A detailed error analysis was completed that accounts for the errors in weighing the specimens as well as the errors in measuring the area (LL040502512251.099 and LL040907112251.122). Our weighing facilities are capable of measuring weight changes to \pm 0.00003 grams, which corresponds to $15 \mathrm{~nm}$ of metal loss over the area of the foil samples. Each environment contained 3-4 foil specimens. Because the standard deviation for the weight loss for these specimens was several orders of magnitude greater than the measurement error, the observed variation is shown in the plots.

\subsubsection{Surface Analysis Techniques}

To characterize the three-dimensional composition of the oxide, several techniques were employed. Surface sensitive techniques such as x-ray photoelectron spectroscopy (XPS) were used to evaluate the elemental composition and oxide stoichiometry over a large $\left(\mathrm{mm}^{2}\right)$ area but for a shallow depth (nanometers). Auger electron spectroscopy measures elemental composition from a range of areas $\left(\mathrm{nm}^{2}\right.$ to $\mathrm{mm}^{2}$ ) with similar depth resolution. Both of these techniques can be used to create depth profiles due to their fine depth resolution; however, in this report, we utilize only Auger depth profiling. Cross-sectional TEM provides the structure, layering, thickness, and degree of crystallinity of the oxide layer, but for a limited area of the surface. Electron energy loss spectroscopy (EELS) within the TEM provides non-quantitative elemental mapping. Atomic force microscopy is used to obtain surface topographic maps with a lateral range of $\sim 100 \mu \mathrm{m}$ and a height resolution of $0.1 \mathrm{~nm}$.

XPS is a surface-sensitive analysis method used here to determine the elemental composition and the chemical state of oxides formed on Alloy 22 coupons. Photoelectrons are generated within the x-ray penetration depth (typically many microns), but only the photoelectrons within the top three photoelectron escape depths are detected. Escape depths are on the order of 15-35 $\AA$, which leads to an analysis depth 
of $\sim 50-100 \AA$. Typically, 95\% of the signal originates from within this depth. All XPS measurements were performed on a PHI Quantum 2000 Quantum Scanning ESCA Microprobe using a monochromatic $\mathrm{Al} \mathrm{K}$ a source with photon energy of $1486.6 \mathrm{eV}$. The analysis area was $1400 \mu \mathrm{m} \times 300 \mu \mathrm{m}$. Spectra were charge-corrected by aligning the chromium $\mathrm{Cr} 2 \mathrm{p} 3$ peak at $577.0 \mathrm{eV}$ or the carbon $\mathrm{C} 1 \mathrm{~s}$ peak at $284.8 \mathrm{eV}$.

Cross-sectional views of the metal-oxide interface were obtained using TEM. Samples were prepared using a focused ion beam "pluck-out" method. Before the focused ion beam is used, a layer of gold-palladium ( $\mathrm{Au}-\mathrm{Pd})$ is evaporated onto the surface to protect the oxide from beam damage during sample preparation. A much thicker platinum $(\mathrm{Pt})$ coating is then deposited using ion-assisted deposition. Both the $\mathrm{Au}-\mathrm{Pd}$ and Pt layers can be seen in the TEM images. The Au-Pd layer, which appears dark in the bright field images shown later in this report, can be used to mark the outer boundary of the oxide. Bright field images were obtained using a FEI-Philips TEM Model CM300FEG. Images display general oxide structure and can be used to quantify oxide thickness. Samples are typically $3 \mu \mathrm{m}$ long, and images are obtained along the entire length of the sample. Images can also be correlated with elemental maps. All images shown in this report can be found in SN-LLNL-SCI-465-V5 (Hayes, 2004b).

Auger depth profiling was used to obtain elemental composition across the oxide metal interface. All Auger measurements were performed using a PHI 680 Scanning Auger Microprobe. Depth profiles were obtained by alternating an acquisition cycle with a sputter cycle. During the acquisition cycle, selected elemental peak intensities were collected. The sputter cycle removed material from the surface of the sample using a $5-\mathrm{keV} \mathrm{Ar}^{+}$source rastered over a 3-mm $\times 3-\mathrm{mm}$ area. In order to eliminate crater wall effects, we acquired data from a smaller region in the center of the sputtered area. The depth profiles acquired show the etch time on the $\mathrm{x}$ axis. The ion gun conditions were chosen to be consistent with an etch rate of $2.4 \mathrm{~nm} / \mathrm{min}$ on a thermally grown silicon dioxide ( $\mathrm{SiO}_{2}$-equivalent depths). Different materials will etch at different rates dependent on surface topography, crystallographic orientation, and incident ion-beam angle. Actual depths in these materials could not be provided.

\subsubsection{Results and Discussion}

\subsubsection{General Corrosion of Alloy 22 from 120 to $220^{\circ} \mathrm{C}$}

Figure 6 shows general corrosion rates calculated from weight-loss measurements from all autoclave and bomb tests as a function of nitrate/chloride ratio, temperature, and duration, for both samples immersed in aqueous solution and samples suspended in the overlying vapor phase. The major finding is that all corrosion rates are significantly less than 0.25 micron per year for all temperatures and environments tested. Macroscopically, rates appear to increase at higher temperature and at the highest nitrate/chloride ratios. However, quantification of the observed trends is limited, because incomplete removal of oxide layers during the cleaning yields negative calculated corrosion rates at temperatures at or below $140^{\circ} \mathrm{C}$. As a whole, the samples held in solution had slightly higher corrosion rates than those held in vapor. Duration of experiment generally yielded similar corrosion rates, except for samples held at $220^{\circ} \mathrm{C}$ in solutions with a $\mathrm{NO}_{3} / \mathrm{Cl}$ ratio of 0.3 . Corrosion rates in these samples increase with the duration of the experiment for both the solution and vapor environments. 


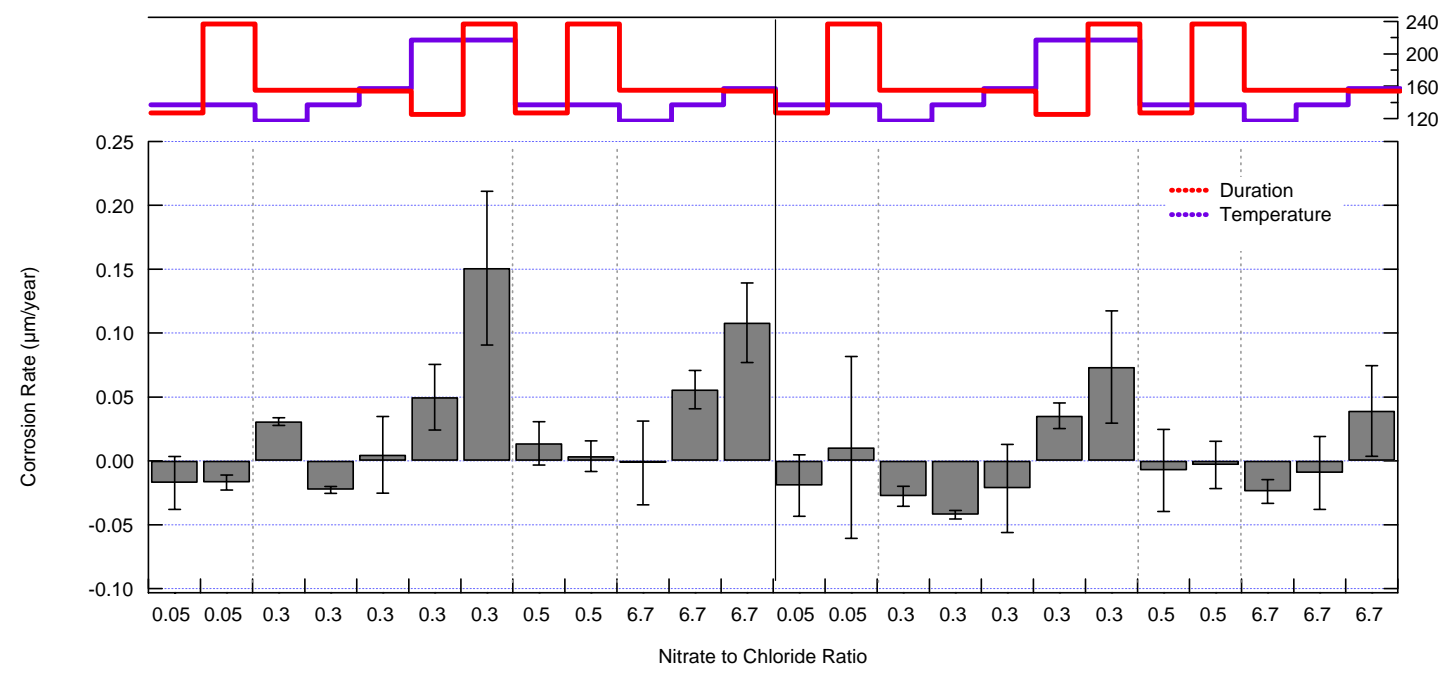

Source: LL040502512251.099 and LL040907112251.122.

Note: The temperature $\left({ }^{\circ} \mathrm{C}\right.$, blue line) and duration (days, red line) are plotted at the top with a shared axis on the right hand side of the graph. Each measurement is an average of 3-6 different samples. The error bars represent the standard deviations.

Figure 6. Calculated corrosion rates for autoclave samples plotted as a function of nitrate/chloride ratio for samples immersed in the solution (left hand side of vertical black line in the middle of the figure) and suspended in vapor (right hand side of the vertical black line).

We use the Arrhenius law to quantify the temperature dependence of Alloy 22 corrosion rate from our weight-loss experiments. Results are given in Table 4 and a corresponding Arrhenius plot is shown in Figure 7. Application of the Arrhenius law to corrosion implies that the rate $R$ has a temperature dependence of the form:

$$
R=R_{0} e^{E / N_{a} k T}
$$

Here $R_{0}$ is the attempt frequency, $E$ is the activation energy $(\mathrm{kJ} / \mathrm{mol}), N_{a}$ is Avogadro's number $\left(6.022 \times 10^{23}\right.$ atoms $\left./ \mathrm{mol}\right), k$ is Boltzmann's constant $\left(1.380 \times 10^{-26} \mathrm{~kJ} / \mathrm{K}\right)$, and $T$ is temperature $(\mathrm{K})$. When the data (rate values and standard deviations for the temperatures studied) are considered for all positive rates regardless of $\mathrm{NO}_{3} / \mathrm{Cl}$ ratio, a best fit of $E=10.9 \pm 3.1 \mathrm{~kJ} / \mathrm{mol}$ is obtained. This is significantly lower than the value ( $E$ $=25 \mathrm{~kJ} / \mathrm{mol}$ ) used in the current generalized corrosion model (BSC, 2004a). That value was based on the temperature dependence of short-term electrochemical tests. The corrosion rate data for $\mathrm{NO}_{3} / \mathrm{Cl}$ of 0.3125 (red in Figure 7), which is representative of samples with a $\mathrm{Cr}_{2} \mathrm{O}_{3}$ barrier layer, exhibits an activation energy of $8 \pm 8 \mathrm{~kJ} / \mathrm{mol}$. This is less than the $25 \mathrm{~kJ} / \mathrm{mol}$ (black line in Figure 7) that is used in the general corrosion model. A separate fit was performed on the environment with $\mathrm{NO}_{3} / \mathrm{Cl}$ of 6.7 because the surface composition analysis suggests a different dissolution mechanism. An activation energy of $49 \pm 29 \mathrm{~kJ} / \mathrm{mol}$ was calculated for these data. The large uncertainties in 
activation energies reported here is due to the small number of temperatures for which data are available (2-3).

Table 4. Corrosion rate (CR) versus temperature $(T)$ for data in Figure 7.

\begin{tabular}{|c|c|c|c|c|c|c|c|}
\hline $\mathrm{NO}_{3} / \mathrm{Cl}$ & $\begin{array}{c}T \\
\left({ }^{\circ} \mathrm{C}\right)\end{array}$ & $\begin{array}{c}T \\
(\mathrm{~K})\end{array}$ & $\begin{array}{c}\text { CR } \\
\text { ( } \mu \mathrm{m} / \text { year) }\end{array}$ & $\begin{array}{c}\sigma_{C R}^{(1)} \\
(\mu \mathrm{m} / \text { /year) }\end{array}$ & $\ln (\mathrm{CR})^{(2)}$ & $\begin{array}{c}\text { Error }^{(3)} \\
\left(\sigma_{C R} / \mathrm{CR}\right)\end{array}$ & $1 / \mathrm{N}_{\mathrm{a}} k T^{(4)}(\mathrm{mol} / \mathrm{kJ})$ \\
\hline 0.3125 & 120 & 393.2 & 0.031 & 0.003 & -3.479 & 0.099 & 0.31 \\
\hline 0.3125 & 140 & 413.2 & -0.023 & 0.003 & & -0.119 & 0.29 \\
\hline 0.3125 & 160 & 433.2 & 0.005 & 0.030 & -5.339 & 6.242 & 0.28 \\
\hline 0.3125 & 220 & 493.2 & 0.050 & 0.026 & -3.001 & 0.518 & 0.24 \\
\hline 6.7 & 120 & 393.2 & -0.002 & 0.033 & & -20.323 & 0.31 \\
\hline 6.7 & 140 & 413.2 & 0.056 & 0.015 & -2.887 & 0.271 & 0.29 \\
\hline 6.7 & 160 & 433.2 & 0.108 & 0.031 & -2.225 & 0.288 & 0.28 \\
\hline
\end{tabular}

${ }^{1}$ This is the standard deviation of the corrosion rate.

${ }^{2}$ This is the natural logarithm of the corrosion rate. The logarithm of a negative number is undefined and is shown as blank in the table for the two points with weight gains.

${ }^{3}$ The propagated error for $\ln (\mathrm{CR})$ is $\sigma_{C R} / C R$.

${ }^{4} \mathrm{~N}_{\mathrm{a}}$ is Avogadro's number $\left(6.022 \times 10^{23}\right.$ atoms/mol), $k$ is Boltzmann's constant $\left(1.380 \times 10^{-26} \mathrm{~kJ} / \mathrm{K}\right)$, and $T$ is temperature $(\mathrm{K})$. The product $N_{a} k$ is the gas constant, which is commonly represented by $R$ (a symbol that is used in this report to represent instead the corrosion rate).

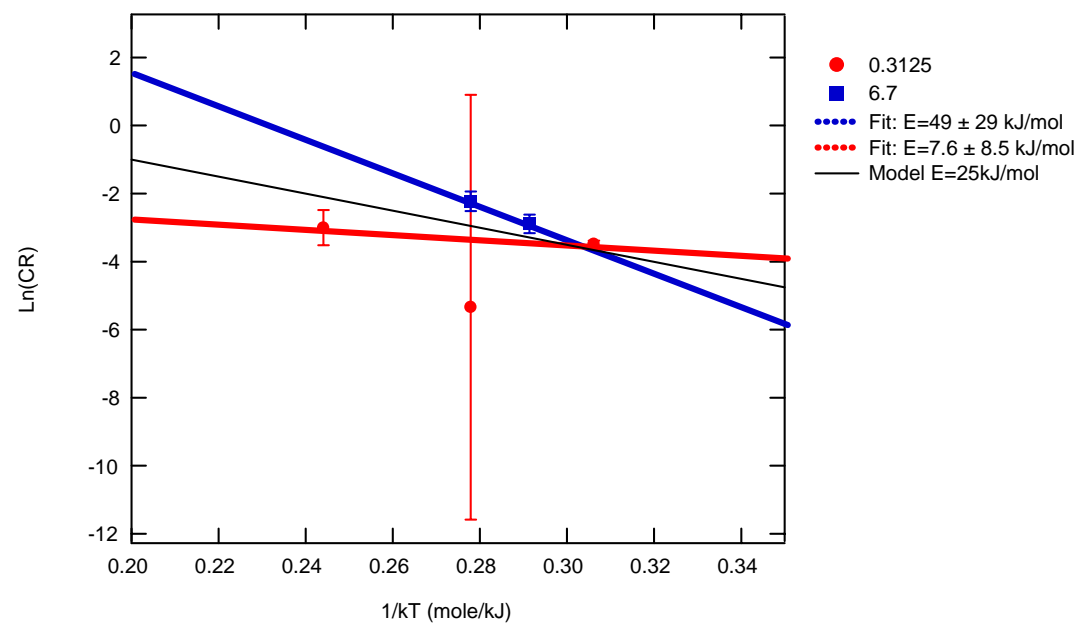

Source: This document.

Note: The activation energy $(\mathrm{kJ} / \mathrm{mol})$ is the negative of the slope. The abscissa is mislabeled " $1 / k T$ "; the quantity here is actually $1 / N_{a} k T$.

Figure 7. Arrhenius plot of corrosion rates for samples held in solutions with a nitrate/chloride ratio of 0.3125 (red) and 6.7 (blue). The black line shows the activation energy used in the general corrosion model corrosion model. The activation energy obtained by combining the data for all $\mathrm{NO}_{3} / \mathrm{Cl}$ ratios $(10.9 \pm 3.1 \mathrm{~kJ} / \mathrm{mol})$ is not shown on this plot. 
As expected from an Arrhenius rate law, the highest corrosion rates (both for samples held in solution and in vapor) were found at the highest temperature, $220^{\circ} \mathrm{C}$. Less intuitively, the next highest corrosion rates were observed in environments with the highest nitrate/chloride ratio, 6.7. This requires some explanation, because nitrate is often considered a corrosion inhibitor. If we consider only the $\mathrm{NO}_{3} / \mathrm{Cl}=6.7$ rate data, then $E=$ $49 \pm 29 \mathrm{~kJ} / \mathrm{mol}$. This value was based on rate data for two temperatures differing by only $20^{\circ} \mathrm{C}$ (data for a third point was not used because it showed a weight gain). Both the change in activation barrier and the higher corrosion rates can be explained by considering the surface composition data, which will be examined below.

\subsection{Evaluation of surface oxides of autoclave samples}

In this section, we describe the results of various surface analysis techniques to characterize surface film composition (XPS), the structure and thickness of the surface oxide (cross-sectional TEM), and composition through the oxide film (Auger depth profiling) formed on Alloy 22 when reacted in solution and in overlying vapor for 4 and 9 months with solution $\mathrm{NO}_{3} / \mathrm{Cl}$ ratios of 0.05 to 6.7 and with temperatures ranging from 120 to $220^{\circ} \mathrm{C}$. Unlike the weight-loss specimens, these samples were only rinsed with Millipore water; thus they represent the surface state prior to the usual cleaning associated with weight-loss analysis.

\subsection{A comparison of surface compositions evaluated by XPS}

XPS was used to evaluate the elemental composition and oxide stoichiometry at the outermost surface film as a function of the atomic percent of the Alloy 22 constituents (Ni, Cr, Mo, W, Fe) for all of the reacted Alloy 22 foils. Results are given in Table 5.

Curve fits of individual high-resolution spectra were used to distinguish contributions from zero-valent metal, oxides, and hydroxides. Figure 8 shows the composition of the surface oxide and/or hydroxide after the metallic contribution was removed. The XPS results are graphed in the figure by nitrate/chloride ratio, temperature, and duration for both the solution and vapor phase studies. With the exception of two samples (DEA700 and JE1343), all of the specimens had a surface oxide primarily composed of $\mathrm{Ni}(\mathrm{OH})_{2},(70-95 \%)$ followed by various chromium oxides (3-19\%). On most samples, significantly lower and varying levels of molybdenum oxide, primarily as $\mathrm{MoO}_{3}$ (or molybdate) were also found. Most, but not all, of the samples had low levels of $\mathrm{Fe}$ (presumably as an oxide) and trace levels of $\mathrm{W}$.

Two subtle differences are apparent between the data sets for immersed (in liquid phase) and suspended (in vapor phase): (1) the surfaces of samples suspended in the vapor phase contain significantly more molybdenum oxide than those of samples immersed in solution; and (2) the nickel/chromium ratio in the oxide (surface) layer increases with aging time for those suspended in vapor but decreases for samples immersed in solution. These differences appear to be due to the fact that the vaporsuspended specimens react with only a thin film of fluid whereas solution-immersed specimens react with a large volume of liquid. Aside from possible differences in $\mathrm{pH}$ or salt concentration, which we view as unlikely due to the high humidity, the vaporsuspended samples do not have a pathway for dissolving low-solubility metal ions. 
Table 5. Autoclaved samples evaluated by XPS.

\begin{tabular}{|c|c|c|c|c|c|c|c|c|c|c|}
\hline Sample & $T\left({ }^{\circ} \mathrm{C}\right)$ & $\mathrm{NO}_{3} / \mathrm{Cl}$ & Days & Envir. $^{a}$ & $\begin{array}{c}\mathrm{Ni} \\
\text { oxide }\end{array}$ & $\begin{array}{c}\mathrm{Cr} \\
\text { oxide }\end{array}$ & $\begin{array}{c}\mathrm{Fe}^{\mathrm{b}} \\
\text { oxide }\end{array}$ & $\begin{array}{c}\text { Mo } \\
\text { oxide }\end{array}$ & $\begin{array}{c}\text { W } \\
\text { oxide }\end{array}$ & $\begin{array}{l}\mathrm{Ni} / \mathrm{Cr} \\
\text { oxide }\end{array}$ \\
\hline DEA1046 & 140 & 0.05 & 130 & $3 \mathrm{~L}$ & 73.7 & 19 & 4 & 3 & 0.3 & 3.9 \\
\hline DEA 700 & 140 & 0.05 & 240 & $3 \mathrm{~L}$ & 41.8 & 43.2 & 7.5 & 6.8 & 0.7 & 1.0 \\
\hline DEA702 & 120 & 0.3125 & 158 & $1 \mathrm{~L}$ & 94.5 & 5 & - & 0.4 & 0.1 & 18.9 \\
\hline DEA701 & 140 & 0.3125 & 158 & $1 \mathrm{~L}$ & 81.7 & 13.7 & 4.4 & 0.2 & - & 6.0 \\
\hline JE1367 & 160 & 0.3125 & 157 & $1 \mathrm{~L}$ & 94.7 & 3 & 0.8 & 1 & 0.5 & 31.6 \\
\hline DEA1183 & 220 & 0.3125 & 128 & $1 \mathrm{~L}$ & 90.7 & 3 & 5.9 & 0.4 & $<0.1$ & 30.2 \\
\hline DEA 1137 & 220 & 0.3125 & 240 & $1 \mathrm{~L}$ & 86 & 11.6 & 2.3 & 0.1 & - & 7.4 \\
\hline DEA1015 & 140 & 0.5 & 130 & $4 \mathrm{~L}$ & 84.1 & 8.4 & 6.4 & 1.2 & - & 10.0 \\
\hline JE 1328 & 140 & 0.5 & 240 & $4 \mathrm{~L}$ & 74.5 & 18.7 & 4.5 & 2.1 & 0.1 & 4.0 \\
\hline DEA687 & 120 & 6.7 & 158 & $2 \mathrm{~L}$ & 79.3 & 18.2 & 1.5 & 0.8 & 0.2 & 4.4 \\
\hline JE1317 & 140 & 6.7 & 158 & $2 \mathrm{~L}$ & 88.7 & 8.5 & 2.1 & 0.6 & 0.1 & 10.4 \\
\hline JE1375 & 160 & 6.7 & 157 & $2 \mathrm{~L}$ & 83.9 & 7.3 & - & 8.7 & 0.1 & 11.5 \\
\hline DEA1132 & 140 & 0.05 & 130 & $3 \mathrm{~V}$ & 74.2 & 14.4 & 5.9 & 5.1 & 0.4 & 5.2 \\
\hline DEA 706 & 140 & 0.05 & 240 & $3 \mathrm{~V}$ & 79.7 & 10.4 & 6.1 & 3.6 & 0.3 & 7.7 \\
\hline JE1331 & 120 & 0.3125 & 158 & $1 \mathrm{~V}$ & 71.3 & 15.1 & 6.3 & 6.9 & 0.4 & 4.7 \\
\hline DEA714 & 140 & 0.3125 & 158 & $1 \mathrm{~V}$ & 70 & 14.4 & 8.2 & 6.8 & 0.6 & 4.9 \\
\hline DEA1058 & 160 & 0.3125 & 157 & $1 \mathrm{~V}$ & 86.6 & 10.3 & 2.1 & 1 & - & 8.4 \\
\hline JE1306 & 220 & 0.3125 & 128 & $1 \mathrm{~V}$ & 78.9 & 17.7 & 1.8 & 1.7 & - & 4.5 \\
\hline JE 1372 & 220 & 0.3125 & 240 & $1 \mathrm{~V}$ & 83.4 & 14.2 & 1.5 & 0.8 & $<0.1$ & 5.9 \\
\hline DEA1181 & 140 & 0.5 & 130 & $4 \mathrm{~V}$ & 69.8 & 16.4 & 7.7 & 5.4 & 0.7 & 4.3 \\
\hline DEA 1007 & 140 & 0.5 & 240 & $4 \mathrm{~V}$ & 75.3 & 11.4 & 8.7 & 4.4 & 0.3 & 6.6 \\
\hline JE1343 & 120 & 6.7 & 158 & $2 \mathrm{~V}$ & 26 & 43.6 & 14.1 & 14.8 & 1.5 & 0.6 \\
\hline DEA712 & 140 & 6.7 & 158 & $2 \mathrm{~V}$ & 80 & 15.9 & 3 & 0.9 & 0.2 & 5.0 \\
\hline JE1352 & 160 & 6.7 & 157 & $2 \mathrm{~V}$ & 84.4 & 11 & - & 4.6 & $<0.1$ & 7.7 \\
\hline
\end{tabular}

Source: LLNL, 2004a, b.

"The solution number (e.g., 2 as in " $2 \mathrm{~L}$ ") corresponds to one of the entries in Table 2. " $\mathrm{L}$ " and " $\mathrm{V}$ " indicate that the sample was immersed in the liquid phase or suspended in the vapor phase, respectively.

${ }^{\mathrm{b}}$ For the purposes of this calculation, all detected Fe was assumed to be in the form of oxides.

Recalling that the observed oxides are a competition between formation from the base metal and dissolution at the oxide-solution interface, we hypothesize that the vapor oxides represent the case where the dissolution kinetics are very slow compared to samples held in solution. This interpretation suggests that molybdenum oxides form in both solution and vapor environments, but dissolve out of the oxide when a solution pathway is present. Similarly, the nickel to chromium ratio can be interpreted as higher nickel solubility in solution. Analyzing the solutions could test these hypotheses.

Chromium speciation at the surface (Figure 9) was determined by fitting the chromium high-resolution spectra with four peaks associated with the different oxidation states: 0 for metal; +3 as found in $\mathrm{Cr}_{2} \mathrm{O}_{3}, \mathrm{Cr}(\mathrm{OH})_{3}$, or $\mathrm{CrOOH} ;+4$ as found in $\mathrm{CrO}_{2}$; and +6 as found in $\mathrm{CrO}_{3}$. The model chosen uses the minimum number of peaks, which tends to be more approximate than models utilizing a greater number of peaks; however it is 
(a) Solution

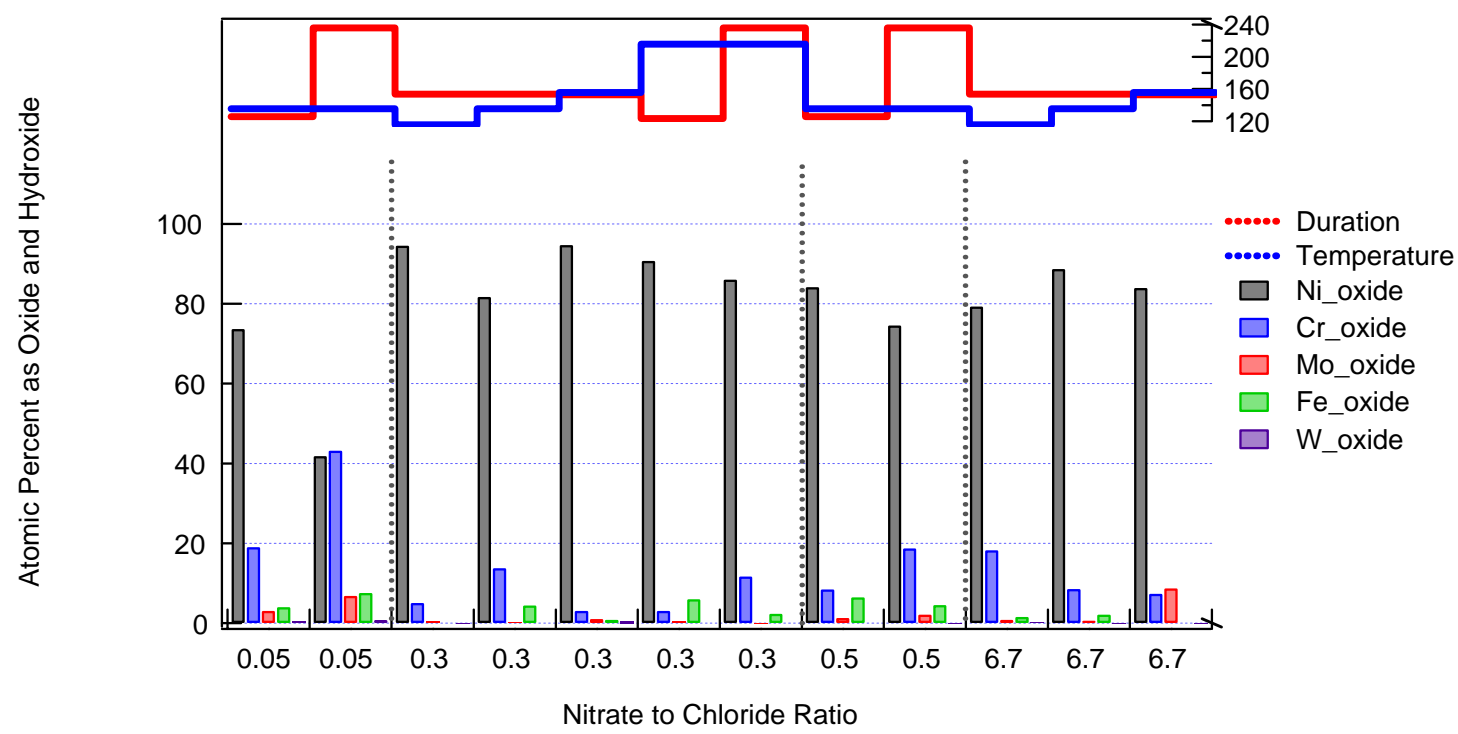

(b) Vapor

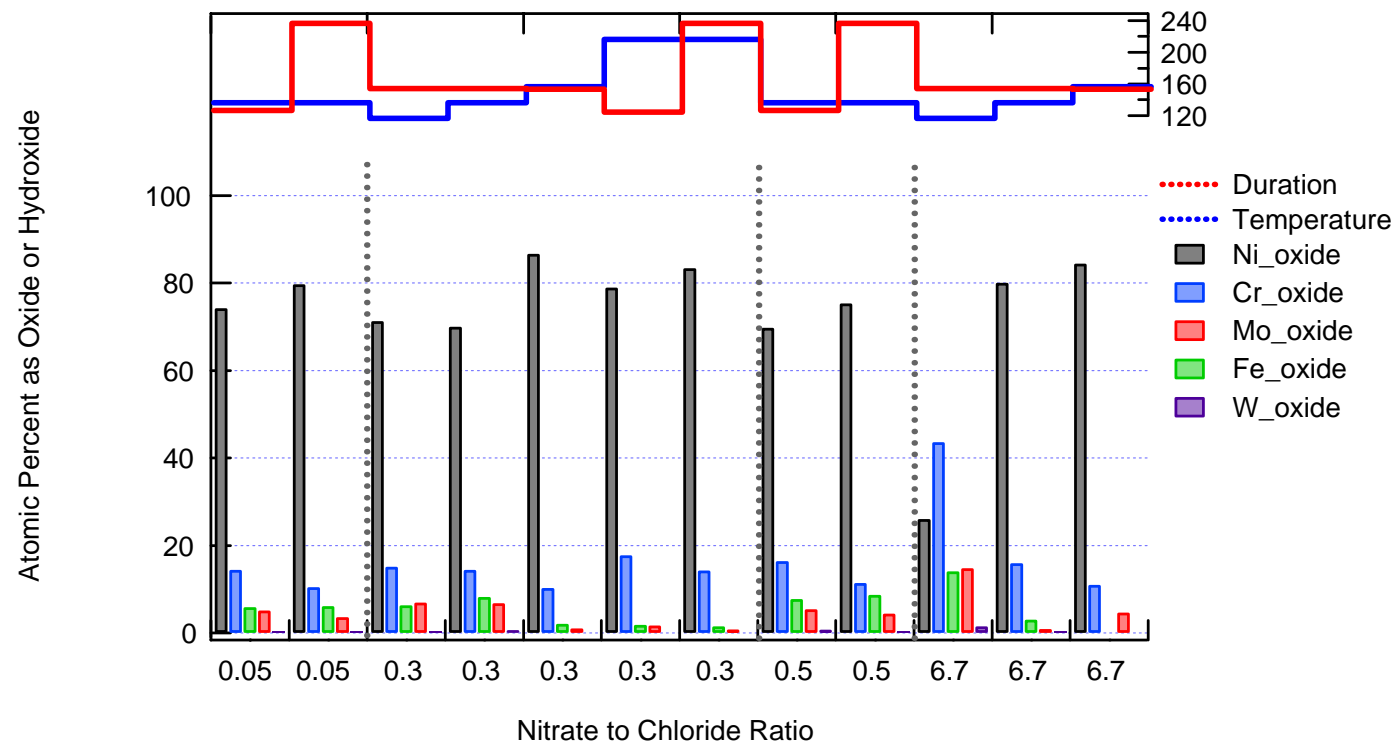

Source: MOL.20041015.0104 and MOL.20041007.0076

Note: The aging duration (days) and temperature $\left({ }^{\circ} \mathrm{C}\right)$ are plotted at the top. Vertical dashed lines mark transitions in solution compositions. Samples were aged in (a) solution and (b) vapor.

Figure 8. Atomic percent of metal ions ( $\mathrm{Ni}, \mathrm{Cr}, \mathrm{Mo}, \mathrm{Fe}, \mathrm{W}$ ) as oxides or hydroxides, displayed as a function of nitrate to chlorine ratio for 24 samples aged in autoclaves and analyzed by XPS. 
more readily applied.. For all but two specimens (JE1375 and JE1352), chromium is predominately in the +3 oxidation state with a chromium spectra similar to that found for electrochemically grown passive oxide films formed at $90^{\circ} \mathrm{C}$ under a variety of electrolyte conditions (BSC, 2004c). However, at the highest $\mathrm{NO}_{3} / \mathrm{Cl}$ ratio of 6.7 and $160^{\circ} \mathrm{C}, \mathrm{Cr}(\mathrm{VI})$ becomes the dominant surface chromium. High weight-loss rates coupled with change in chromium speciation suggest that at higher temperatures, a high nitrate/chloride accelerates the oxidation of the metal. As discussed above, the higher $\mathrm{Cr}(\mathrm{VI})$ levels in the vapor sample likely result from limited dissolution kinetics in thin films, despite the high solubility of $\mathrm{Cr}(\mathrm{VI})$ oxides.

\subsubsection{A Comparison between Brine Solution with Varying $\mathrm{NO}_{3} / \mathrm{Cl}$ Ratio}

More detailed surface analysis was performed on a subset of Alloy 22 samples, because the XPS analysis discussed above only provides compositional information for the outermost surface of the oxide (within a few escape depths of the surface). We combine cross-sectional TEM and Auger depth profiling to compare oxide morphology, composition, and thickness as a function of aging time and brine environment (Table 6).

Table 6. Environmental conditions and identification numbers of autoclaved samples evaluated by XPS, Auger, and TEM

\begin{tabular}{|l|l|l|l|l|l|l|}
\hline $\begin{array}{c}\text { Temperature } \\
\left({ }^{\circ} \mathbf{C}\right)\end{array}$ & \multicolumn{1}{|c|}{$\mathbf{N O}_{3}{ }^{-} \mathbf{C l l}^{-}$} & $\begin{array}{c}\text { Liquid/ } \\
\text { Vapor }\end{array}$ & $\begin{array}{c}\text { Duration } \\
\text { (days) }\end{array}$ & $\begin{array}{c}\text { XPS } \\
\text { Sample ID }\end{array}$ & $\begin{array}{c}\text { Auger } \\
\text { Sample ID }\end{array}$ & $\begin{array}{c}\text { TEM } \\
\text { Sample ID }\end{array}$ \\
\hline 140 & 0.05 & Liquid & 130 & DEA1046 & DEA1046 & DEA1046 \\
\hline 140 & 0.05 & Liquid & 240 & DEA 700 & DEA 700 & DEA1041 \\
\hline \hline 140 & 0.5 & Liquid & 130 & DEA1015 & DEA1015 & \\
\hline 140 & 0.5 & Liquid & 240 & JE 1328 & JE 1328 & DEA1127 \\
\hline 220 & 0.3125 & Liquid & 128 & DEA1183 & DEA1183 & \\
\hline 220 & 0.3125 & Liquid & 240 & DEA 1137 & DEA 1137 & DEA686 \\
\hline
\end{tabular}

Source: Hayes, 2004b.

Comparison of cross-sectional TEM images for Alloy 22 reacted at $140^{\circ} \mathrm{C}$ in $\mathrm{NO}_{3} / \mathrm{Cl}=0.05$ and 0.5 showed similar morphology and oxide thickness. Figures 10 and 11 show cross-sections of the oxide layer at two magnifications for the samples aged 4 months and 9 months. The base metal, oxide, Pd-Au layer, and one or more platinum layers are marked in Figure 10a and are representative of all images shown in this report. The Pd-Au and platinum are due to the sample preparation process. The oxide is a light layer bounded by the thin, dark Au-Pd layer and the base metal. 
(a)

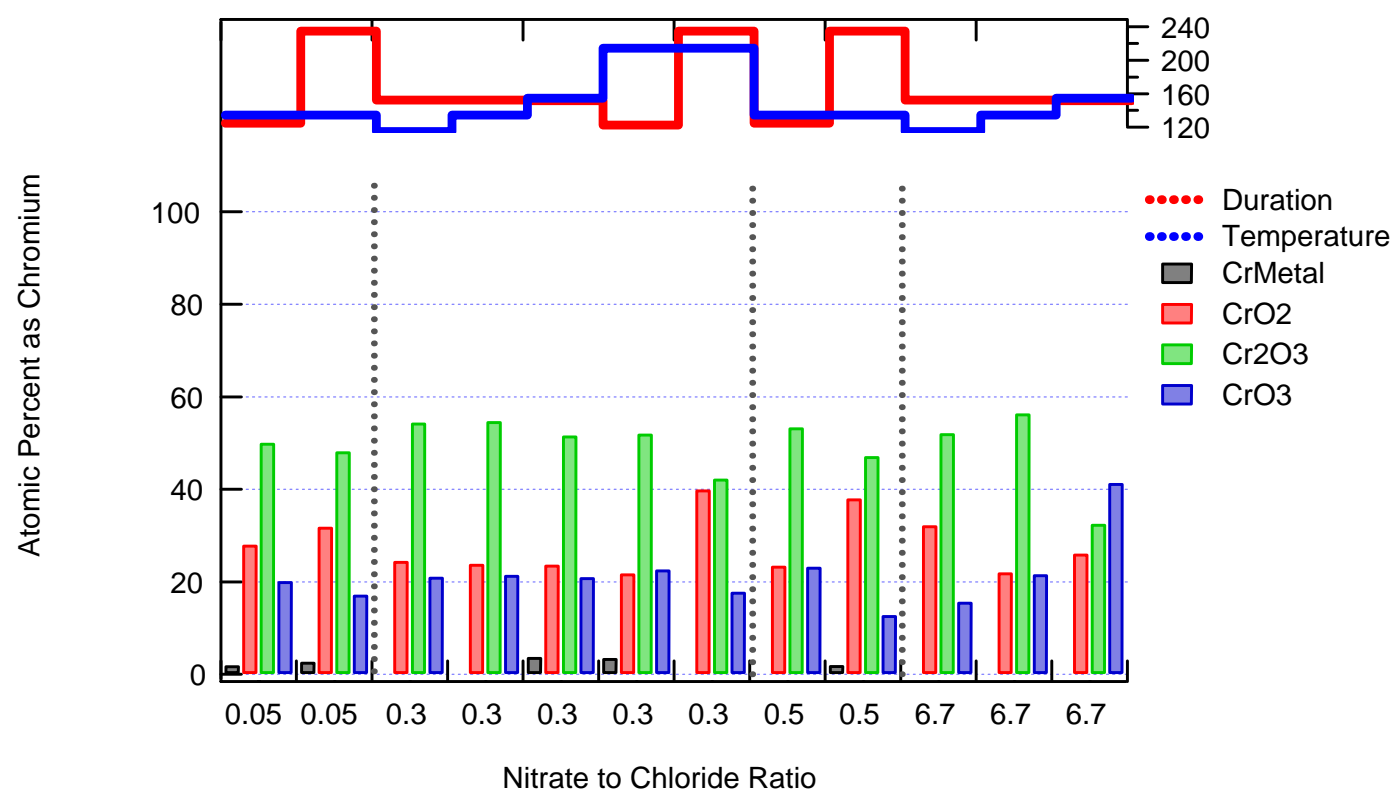

(b)

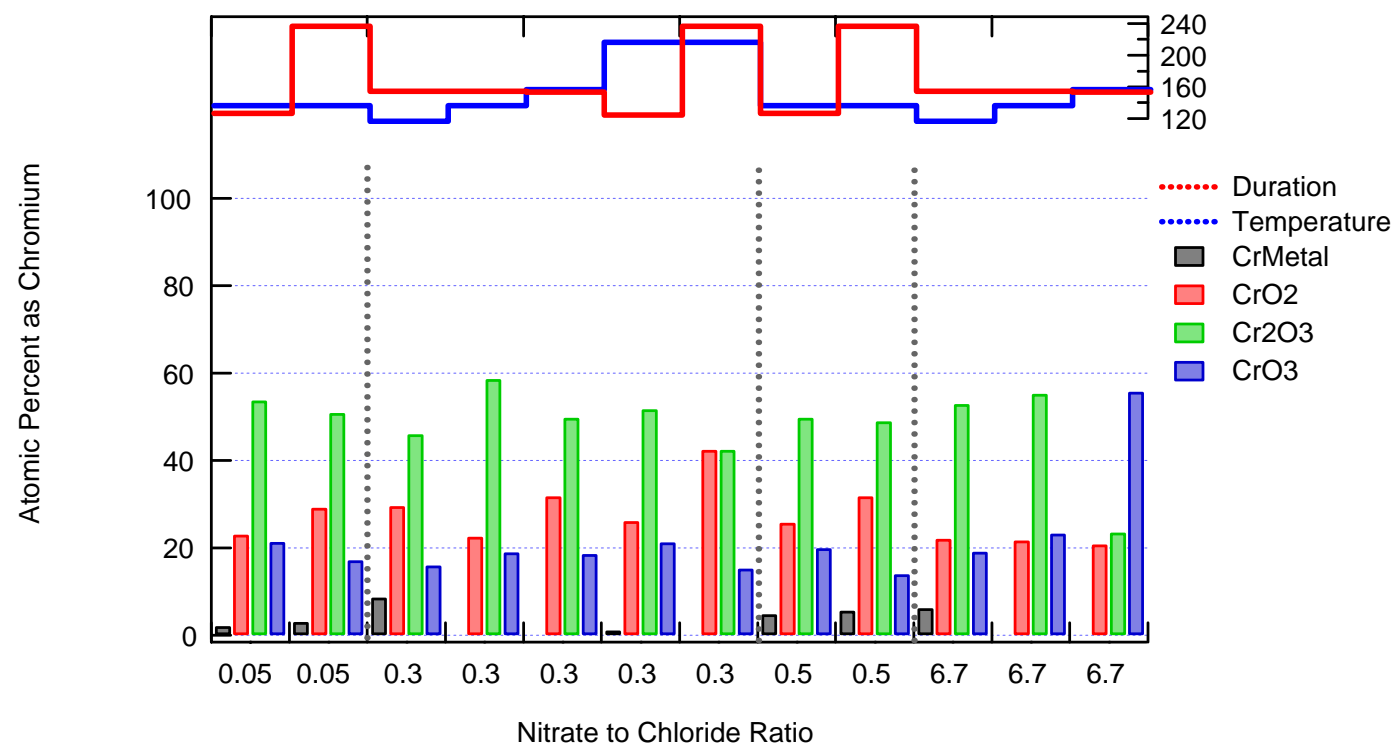

Source: MOL.20041015.0104 and MOL.20041007.0076.

Note: The aging duration (days) and temperature $\left({ }^{\circ} \mathrm{C}\right)$ are plotted at the top. Vertical dashed lines mark transitions in solution compositions.

Figure 9. The chromium composition at the surface of samples aged in autoclaves:

(a) samples immersed in solution and (b) suspended in overlying vapor. 
(a)

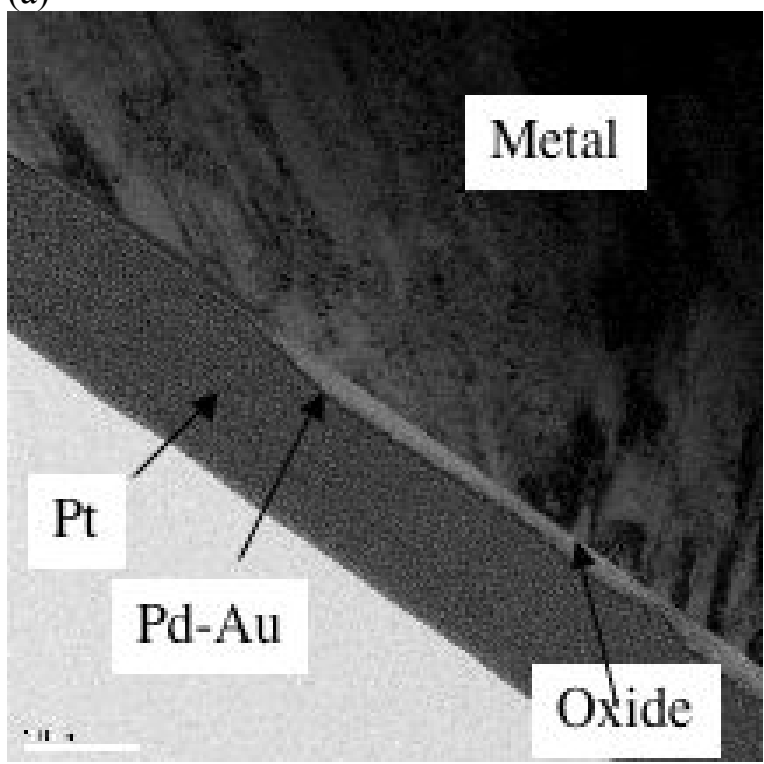

(c)

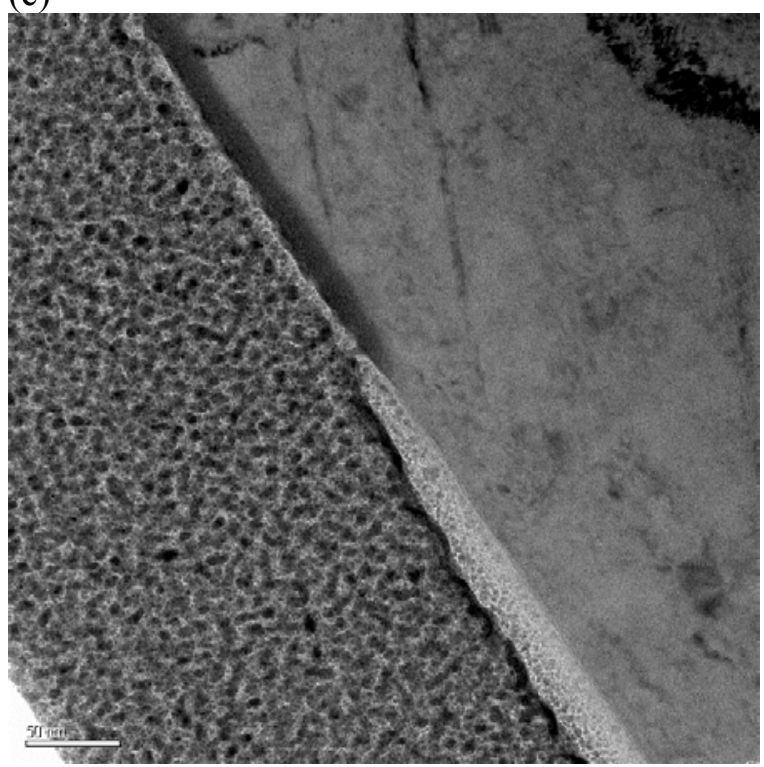

(b)

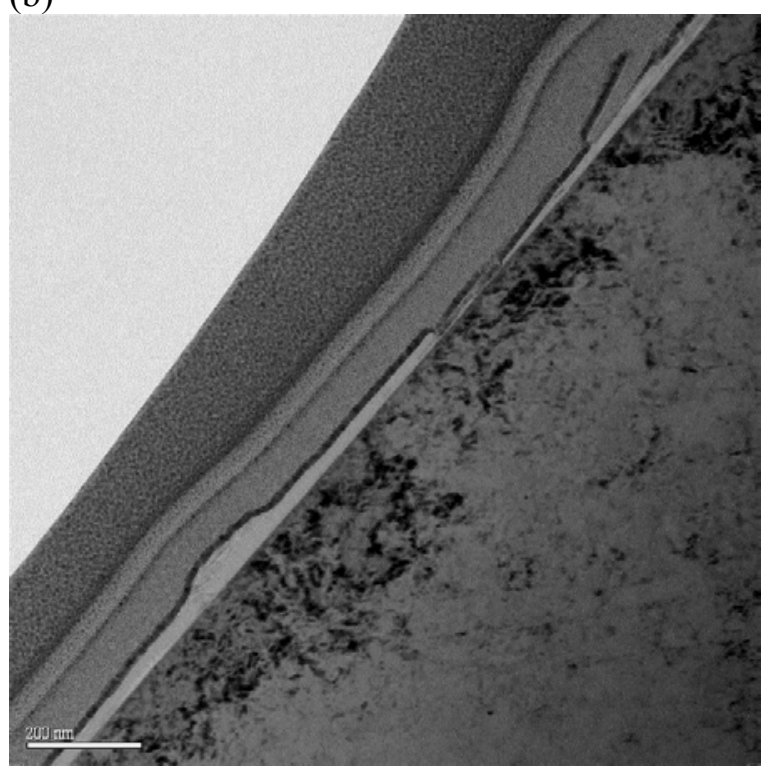

(d)

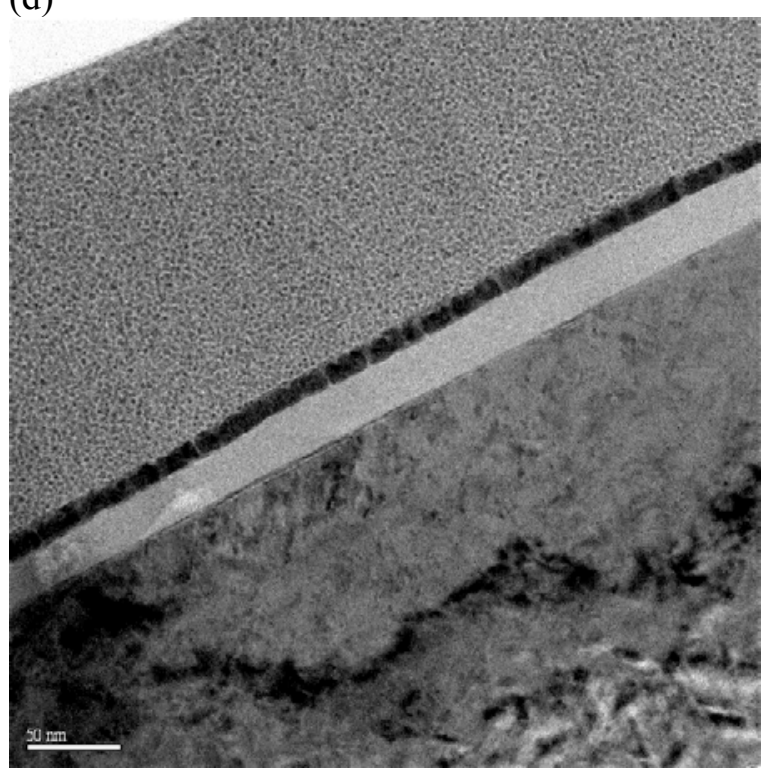

Source: Images from SN-LLNL-SCI-465-V5; Hayes, 2004b.

Note: (a, c) Sample DEA1046, aged $\sim 4$ months. The base metal is at the upper-right part of the image. The oxide is the wavy, light region next to the base metal. (b, d) Sample DEA1041, aged $\sim 9$ months. The base metal is in the lower-right portion of the image. The oxide is the wavy, light region next to the base metal. $(\mathrm{a}-\mathrm{b}) \mathrm{A}$ comparison of the surfaces at $17.5 \mathrm{~K} \times$ magnification. The scale bar is $200 \mathrm{~nm}$ for both images. (c-d) A comparison of the surfaces at $65 \mathrm{~K} \times$ magnification. The scale bar is $50 \mathrm{~nm}$ for both images.

Figure 10. Comparison between 4 months and 9 months of immersion in $140^{\circ} \mathrm{C}$ brine with $\mathrm{NO}_{3} / \mathrm{Cl}=0.05$. 
(a)

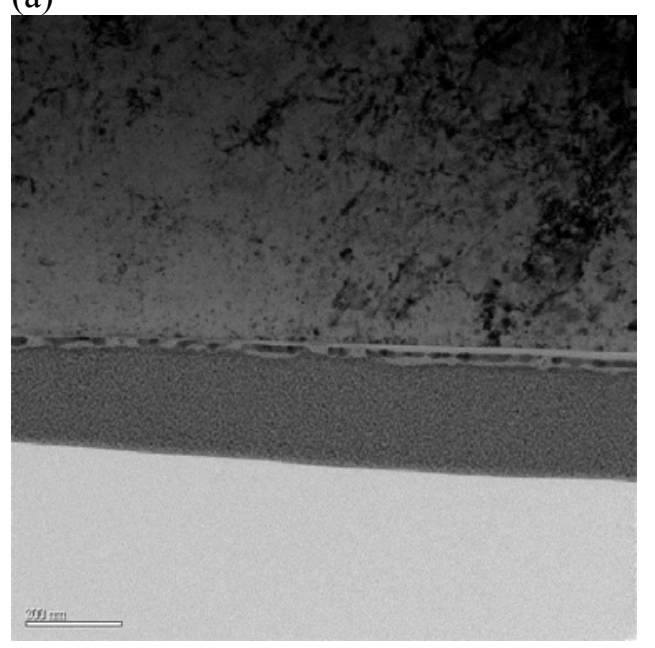

(b)

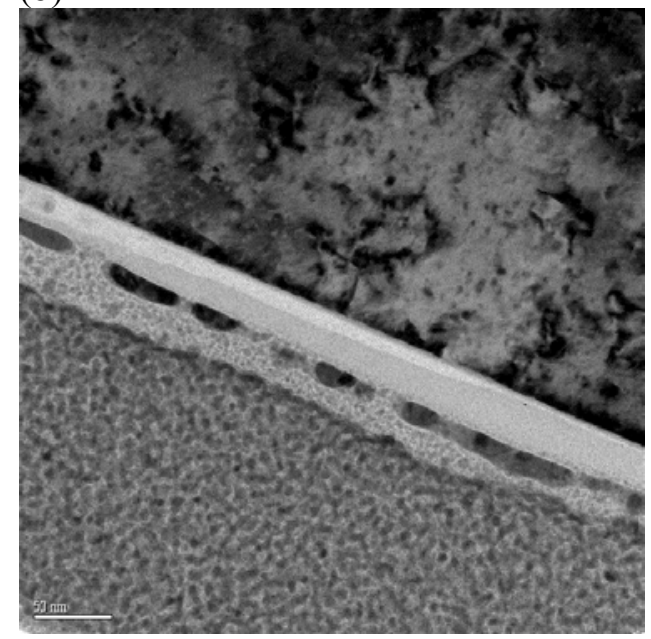

Source: Images from SN-LLNL-SCl-465-V5; Hayes, 2004b.

Note: (a) Magnification $=17.5 \mathrm{~K} \times$ and scale bar $=200 \mathrm{~nm}$; (b) magnification $=65 \mathrm{kX}$ and scale bar $=200 \mathrm{~nm}$. The base metal is at the top side of the image. In image (a), the oxide varies in thickness. In image (b), the oxide is approximately $30 \mathrm{~nm}$. The oxide does not have light and dark regions typical of polycrystalline films and thus is likely amorphous (or polycrystalline on a scale too small to see at these magnifications).

Figure 11. Cross-sectional TEM images of autoclaved sample DEA1127, held for $\sim 9$ months in a $140^{\circ} \mathrm{C}$ brine solution with $\mathrm{NO}_{3} / \mathrm{Cl}$ ratio of 0.5 .

Both the 4-month and 9-month samples held in $\mathrm{NO}_{3} / \mathrm{Cl}=0.05$ environments show considerable variation in their oxide surfaces. This is most apparent from the lowmagnification images in Figure 10a and Figure 10b. In the $\sim 3-\mu \mathrm{m}$ region where the TEM images were obtained, the oxide thickness varies from 0-60 nm. From the higher magnification images in Figure 10c and Figure 10d, the oxide appears less porous and more homogeneous at later times. The metal remains smooth in both cases. SEM analyses (Figure 12) suggest that variation in oxide thickness is due to variation of Nirich oxides over the surface. This is supported by small-spot Auger analysis (not shown) of sample DEA700, which shows that the brighter, upraised regions had more nickel and less chromium than the darker regions. This analysis suggests that the mottled appearance is due to a nickel-rich oxide that deposits in islands on the surface. From the SEM images, it appears that at the earlier times, small islands are distributed across the surface. At later times, these partially coalesce, creating larger regions of nickel-oxide as well as larger regions without this deposit. Auger depth profiles (not shown) for all metal constituents of Alloy 22 and the solution salts show that the surface is predominately composed of nickel, chromium, and oxygen (aside from carbon silicon and aluminum contaminants). The surface contains no significant chloride. 
(a)

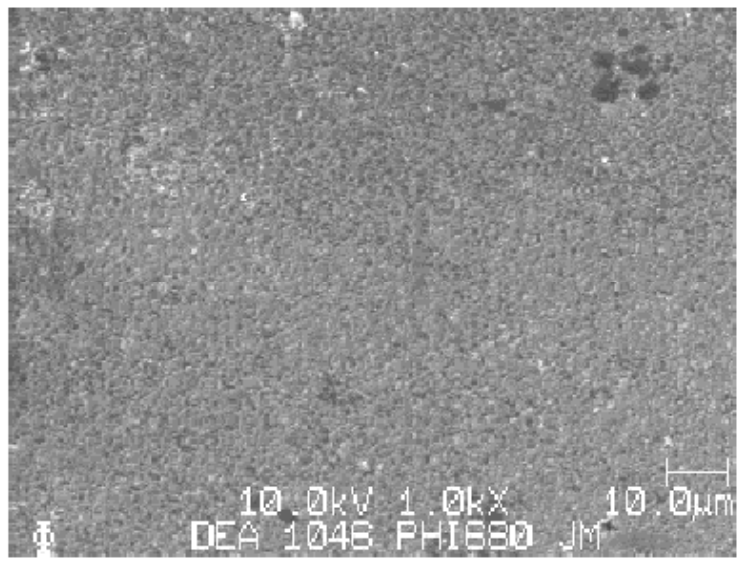

(b)

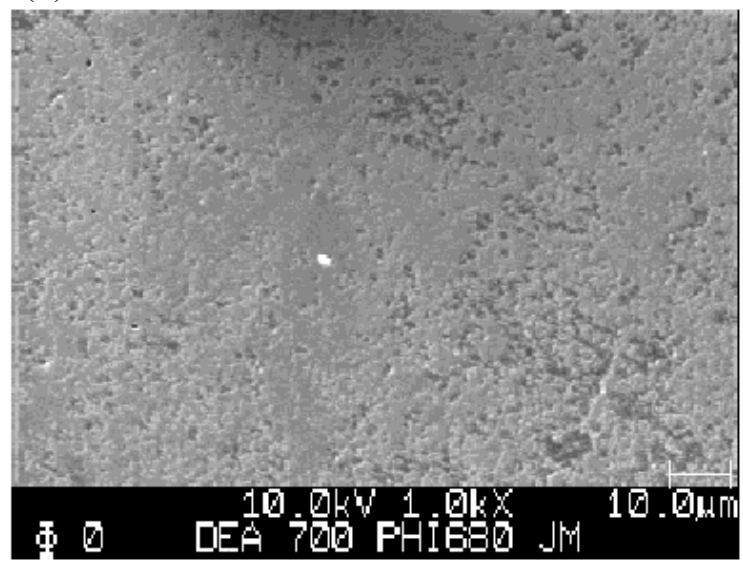

Source: Images from Charles Evans report C04J4575; MOL.20041101.0419.

Note: The images are non-Q: (a) Sample DEA1046 aged $\sim 4$ months. (b) Sample DEA700 aged $\sim 9$ months. The Auger analysis sampled over an area of $\sim 18 \mu \mathrm{m} \times 13 \mu \mathrm{m}$.

Figure 12. SEM images of surfaces where Auger depth profiling was performed.

At the higher nitrate/chloride ratio of 0.5 , which is high enough to significantly reduce crevice corrosion, the oxide looks very similar to that at low ratios for these noncreviced specimens. The oxide is thinner but non-uniform in thickness, varying from a few nanometers to $\sim 30 \mathrm{~nm}$. It is composed of approximately $75 \%$ nickel, $19 \%$ chromium, $5 \%$ iron, and $2 \%$ molybdenum. Consistently, the corrosion rates at $\mathrm{NO}_{3} / \mathrm{Cl}$ ratios of 0.05 and 0.5 are approximately the same. This suggests that the low acid conditions of a creviced specimen are necessary to observe differences in corrosion rates due to $\mathrm{NO}_{3} / \mathrm{Cl}$ ratio in the range of 0.05 to 0.5 .

In contrast to the fairly thin, non-uniform oxide layer at $140^{\circ} \mathrm{C}$, cross-sectional TEM images (Figure 13) show that a very thick $(0.5 \mu \mathrm{m})$ oxide has formed on the Alloy 22 surface in solutions with $\mathrm{NO}_{3}{ }^{-} / \mathrm{Cl}^{-}=0.3$ at the highest temperature tested, $220^{\circ} \mathrm{C}$. It is clear from the ragged appearance of the base-metal that the metal has corroded and transformed into a stratified oxide. This oxide is more than 10 times thicker than the oxides formed at $140^{\circ} \mathrm{C}$ in solutions that bound this nitrate to chloride ratio, which suggests that temperature rather than $\mathrm{NO}_{3}{ }^{-} / \mathrm{Cl}^{-}$ratio is responsible for the dramatically different oxide formation.

The oxide has four distinct oxide layers within it. Three of the layers have different morphologies that can be seen in the bright field images. These are clearest in Figure 13a, which shows an apparently homogeneous $\sim 0.2 \mu \mathrm{m}$ thick oxide layer nearest the jagged base metal followed by a lighter, still uniform oxide that is $\sim 0.08 \mu \mathrm{m}$ thick, and a thicker $(\sim 0.2-0.25-\mu \mathrm{m}$-thick) mottled layer. The mottled pattern is an indication that this outermost layer is polycrystalline. From the XPS studies, the outer layer is identified as $\mathrm{Ni}(\mathrm{OH})_{2}$. The fourth layer is deduced from the oxygen, chromium, and 
(a)

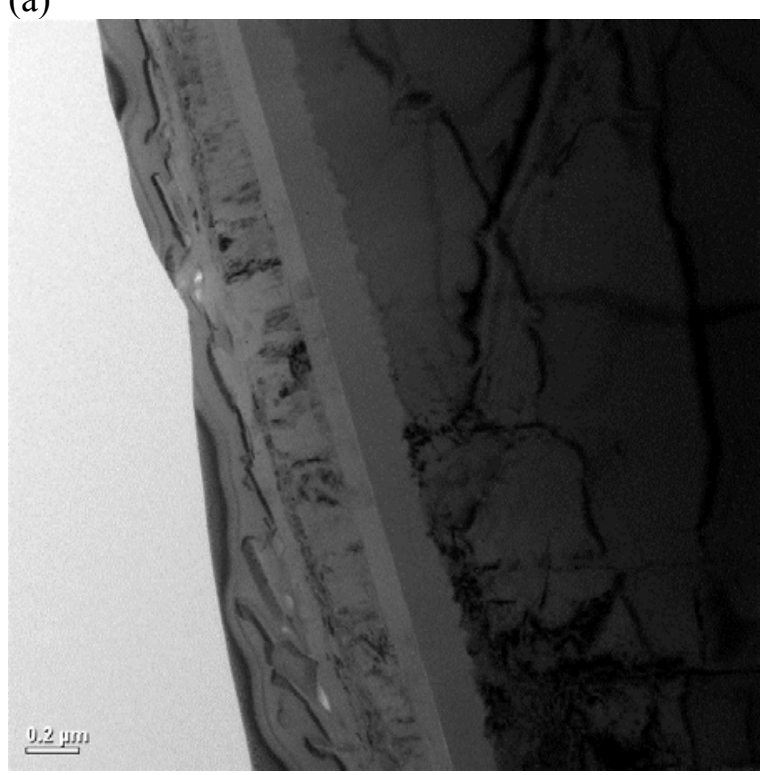

(b)

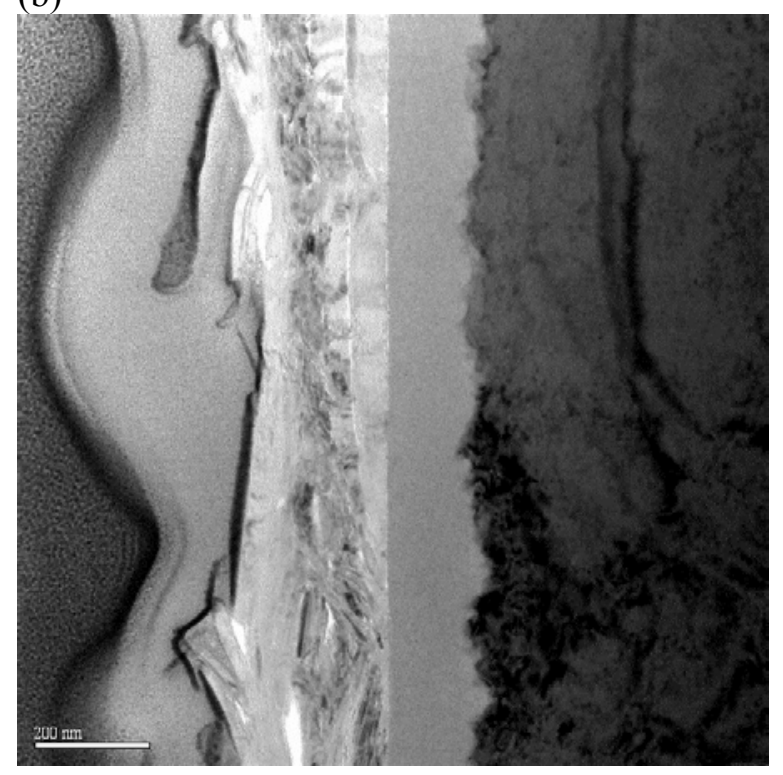

Source: Images from SN-LLNL-SCl-465-V5; Hayes, 2004b.

Note: (a) Magnification $=8.8 \mathrm{~K} \times$ with scale bar $=0.2 \mu \mathrm{m}$. (b) Magnification $=17.5 \mathrm{~K} \times$ and scale bar $=$ $200 \mathrm{~nm}$. The metal is at the right side of the image. Three separate oxide layers can be seen between the partially fractured, dark Pd-Au sputtered layer and the base metal. The layers are best seen in (a), where the total oxide thickness varies from $\sim 0.5-0.6 \mu \mathrm{m}$ over the imaged region.

Figure 13. Cross-sectional TEM images of autoclaved sample DEA686, held for $\sim 9$ months in a $220^{\circ} \mathrm{C}$ brine solution with $\mathrm{NO}_{3} / \mathrm{Cl}$ ratio of 6.7 .

nickel elemental maps in Figure 14. In particular, the chromium map in Figure 14d has an enriched chromium region at the base-metal boundary while the nickel map has a dark, denuded region. Together these data suggest that a thin, conformal chromium oxide layer (presumably $\mathrm{Cr}_{2} \mathrm{O}_{3}$ ) exists similar to what is found in passive film studies over a wide range of solution conditions.

The four layers are labeled and shown schematically in Figure 14a. From the elemental maps, it is difficult to determine compositional differences between the layers 2 and 3 in Figure 14a. It is clear that both of these layers contain chromium although the concentrations are lower than the bright line of conformal $\mathrm{Cr}_{2} \mathrm{O}_{3}$ in layer 1 . The nickel elemental map also shows that layers 2 and 3 contain nickel at a level less than the $\mathrm{Ni}(\mathrm{OH})_{2}$ polycrystalline layer and more than the dark layer that we identify as $\mathrm{Cr}_{2} \mathrm{O}_{3}$. This is supported by the Auger depth profile (Figure 15). These layers are likely a mixed oxide with nickel, chromium, and perhaps molybdenum content. 
(a)

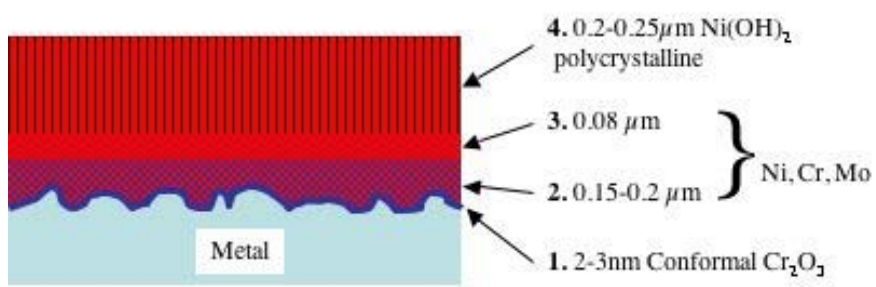

(b)

(c)
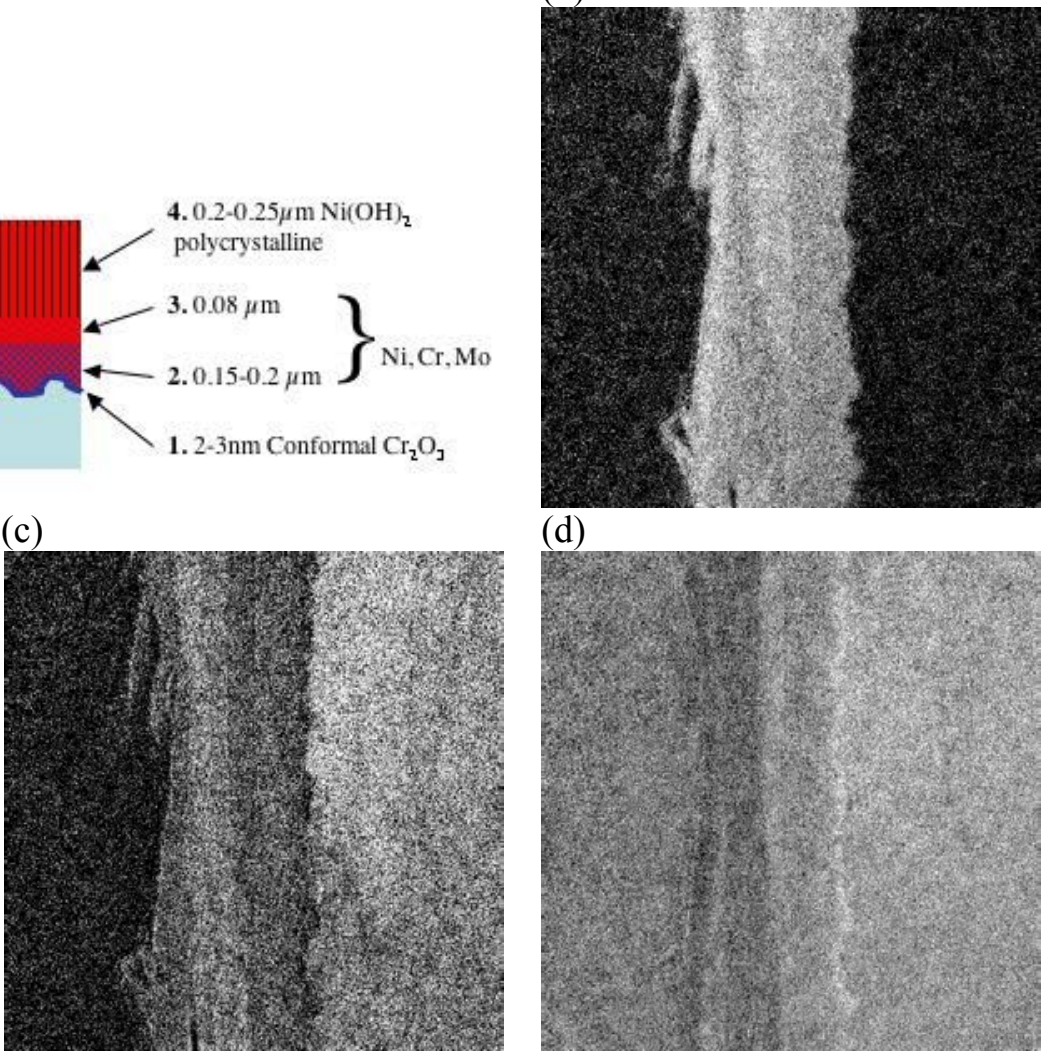

(d)

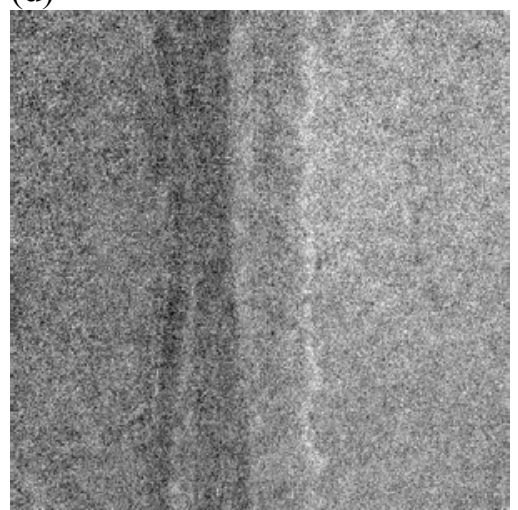

Source: Images are from SN-LLNL-SCl-465-V5; Hayes, 2004b.

Note: The region and size scale are approximately the same as those shown in Figure 12b.

Figure 14. (a) Oxide composition of DEA686, shown schematically. Energy electron loss spectroscopic maps provide (b) oxygen, (c) nickel, and (d) chromium composition.

XPS and Auger depth profile were used to compare the 4-month sample with the 9-month sample. From the Auger depth profile (Figure 15), the stratified layers are less evident than those seen in the TEM images. This is because Auger electrons come from a range of depths and because surface roughness smears the interfaces. The 9-month samples have a thicker oxide than the 4-month samples as one would normally expect, and the overall composition profile is similar for both time points. Both samples show the nickel-rich outer oxide with increased chromium in the oxide approaching the metal substrate. From XPS analysis of the surfaces, the samples are predominately nickel in the form of $\mathrm{Ni}(\mathrm{OH})_{2}$. Both samples show some iron (3-6\%) in the nickel layer, very little molybdenum $(<0.5 \%)$, and almost no tungsten $(<0.1 \%)$. The $\mathrm{Ni} / \mathrm{Cr}$ ratio is much higher (30 compared to 7) at the later times, presumably due to the thickening of the $\mathrm{Ni}(\mathrm{OH})_{2}$ layer with time. From XPS analysis (Table 5), the two samples aged in vapor had surface compositions that were almost the same for both time points and were most similar to the 4 -month solution sample. In particular, the $\mathrm{Ni} / \mathrm{Cr}$ ratios were $\sim 6$. This suggests that either 
the $\mathrm{Ni}(\mathrm{OH})_{2}$ layer does not thicken to the same degree in vapor, or nickel at the oxidesolution interface preferentially leaches into solution, which it cannot do in the vapor phase.

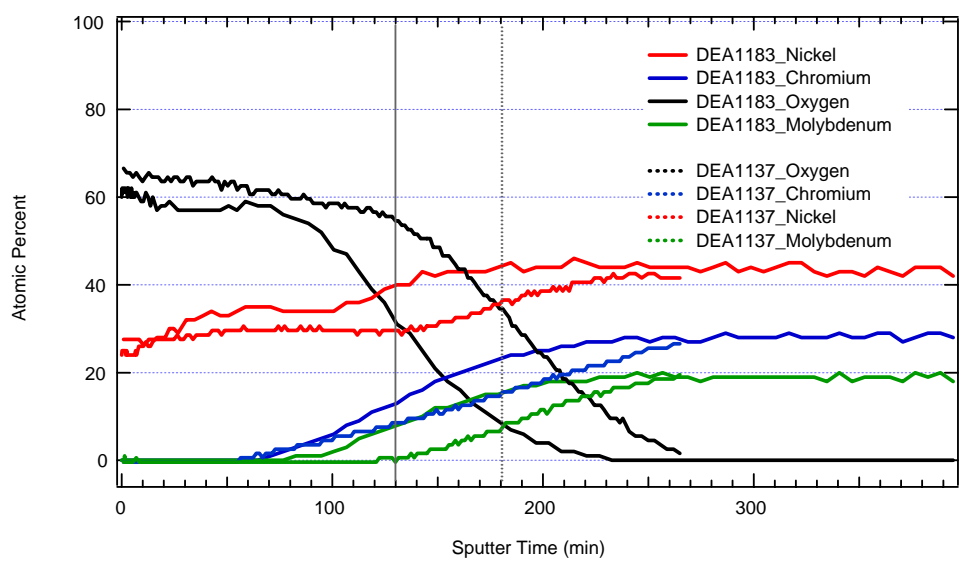

Source: Data from Charles Evans report C04J4575; MOL.20041015.0104. Note: The vertical lines show the approximate locations of the oxide-metal interfaces as determined by the full width at half maximum method. From the Auger profiles, the sample aged $\sim 4$-months (solid curves) has a thinner oxide than the sample aged for longer times (dashed curves), as expected. Data are normalized to $100 \%$ of elements detected, but only nickel, chromium, molybdenum, and oxygen are plotted here.

Figure 15. Auger depth profiles of sample DEA1183 aged $\sim 4$ months and DEA1137 aged $\sim 9$ months in $220^{\circ} \mathrm{C}$ brine solution with $\mathrm{NO}_{3} / \mathrm{Cl}=0.3125$.

In all cases, the data are consistent with a conformal chromium oxide layer at the metal-oxide interface overlaid with $\mathrm{Ni}(\mathrm{OH})_{2}$ islands. The coverage and thickness of the $\mathrm{Ni}(\mathrm{OH})_{2}$ varies with environment and becomes hundreds of nanometers thick at the highest temperatures $\left(220^{\circ} \mathrm{C}\right)$. Given that the corrosion rates do not depend on the whether the $\mathrm{Ni}(\mathrm{OH})_{2}$ completely covers the surface, we conclude that the chromium oxide layer is responsible for the low corrosion rates.

\subsubsection{Implications to the General Corrosion Model}

The program's current general corrosion model includes temperature dependency, but no dependency on solution composition. The associated rate equation relies on longterm weight-loss data to determine the rate constant and short-term electrochemical data to derive the temperature dependence (because no temperature dependence was observed in the 60 and $90^{\circ} \mathrm{C}$ weight-loss studies). Findings from the general corrosion studies highlighted here support this rate model. The new weight-loss data from the present study show a temperature dependency (consistent with an activation energy of $10 \pm 3 \mathrm{~kJ} / \mathrm{mol}$ ) that lies between that observed in the LTCTF measurement, (no dependency; $E=0$ 
$\mathrm{kJ} / \mathrm{mol})$, and the short-term electrochemical tests $(E=25 \mathrm{~kJ} / \mathrm{mol})$. Furthermore, general corrosion rates for Alloy 22 do not appear to be strongly dependent on the $\mathrm{NO}_{3} / \mathrm{Cl}$ ratio except at very high $\mathrm{NO}_{3} / \mathrm{Cl}$ (6.7). Both surface analyses and macroscopic rates are similar for $\mathrm{NO}_{3} / \mathrm{Cl}$ ratios of 0.05 and 0.5 at $140^{\circ} \mathrm{C}$. Thick oxide layers and clear faceting of the metal interface resulting from corrosion at $220^{\circ} \mathrm{C}$ and $\mathrm{NO}_{3} / \mathrm{Cl}=0.3$ further support the model by showing that temperature is more important than the chemical environment for generalized corrosion under these not very acidic conditions. This is not the case for localized corrosion, for which $\mathrm{NO}_{3} / \mathrm{Cl}$ ratios above 0.2 have been shown to inhibit corrosion. The effect of $\mathrm{NO}_{3} / \mathrm{Cl}$ in acid solutions is further discussed in Section 4.

Our data suggest that at very high $\mathrm{NO}_{3} / \mathrm{Cl}$ ratios and high temperature, $\mathrm{NO}_{3}$ enhances general corrosion by enabling the oxidation of $\mathrm{Cr}$ metal to $\mathrm{Cr}(\mathrm{VI})$. This interpretation is based on two samples at $\mathrm{NO}_{3} / \mathrm{Cl}=6.7$ and $160^{\circ} \mathrm{C}$ and limited XPS analyses of surface $\mathrm{Cr}$ speciation. Further work is needed to determine if $\mathrm{NO}_{3}$ contributes to Alloy 22 dissolution in concentrated solutions. Recent work shows that very concentrated brines with high $\mathrm{NO}_{3} / \mathrm{Cl}$ solutions are stable to temperatures above $180^{\circ} \mathrm{C}$ (Carroll et al., 2005).

The role of the oxide film is to limit diffusion between the environment and the metal. In cases where the oxide is stable, the growth is a self-limiting process (i.e., as the film thickens, the diffusion across it slows, and the metal oxidizes at an ever-diminishing rate). In cases where the oxide is not thermodynamically stable, it is dissolving at the oxide-solution interface. As the oxide dissolves, the metal oxidizes at the metal-oxide interface. The system achieves a steady state with a particular oxide thickness when the oxide dissolution and the metal oxidation rates are balanced. Once sufficient metal has transferred to solution, the solution becomes saturated with respect to the oxide, and the driving force for dissolution at the oxide-solution interface stops. The findings of KTI Appendix $\mathrm{N}$ is that Alloy 22 develops a chromium oxide barrier layer in the range of environments tested ( $\mathrm{NaCl}$ and multi-ionic brines at $\mathrm{pH}$ values of approximately 3 to 12 ). The oxide phases expressed are consistent with thermodynamically stable oxides in the passive region. However, given the low metal concentrations in solution, it is more likely that the oxides are kinetically stable, representing the first (steady state) case. Thus, the low general corrosion rates measured in short-term tests are a reflection of the slow dissolution kinetics of chromium oxide and in particular, a chromium oxide in the $3+$ oxidation state, such as $\mathrm{Cr}_{2} \mathrm{O}_{3}$. It is possible that the thin water layer conditions of the vapor specimens can achieve a saturated solution state, but further analysis would be needed to compare the predicted metal ion concentrations in solution with the measured weight loss.

In the high nitrate environment, it appears that either $\mathrm{Cr}_{2} \mathrm{O}_{3}$ partially converts to $\mathrm{CrO}_{3}$, or else $\mathrm{CrO}_{3}$ forms directly from chromium in the base metal. The possible reactions are illustrated by:

$$
\mathrm{Cr}_{2} \mathrm{O}_{3}+2 \mathrm{H}^{+}+2 \mathrm{NO}_{3}^{-}=2 \mathrm{CrO}_{3}+\mathrm{H}_{2} \mathrm{O}+2 \mathrm{NO}(\mathrm{g})
$$

and

$$
2 \mathrm{Cr}^{0}+3 \mathrm{H}^{+}+3 \mathrm{NO}_{3}^{-}=2 \mathrm{CrO}_{3}+3 / 2 \mathrm{H}_{2} \mathrm{O}+3 / 2 \mathrm{~N}_{2} \mathrm{O}(\mathrm{g})
$$


These result in the conversion of $\mathrm{Cr}(0)$ or $\mathrm{Cr}(\mathrm{III})$ to $\mathrm{Cr}(\mathrm{VI})$. Reactions 3 and 4 employ nitrate as the sole oxidant, though oxygen gas could also serve in that role; different $\mathrm{N}$ bearing product species are possible. In addition, because $\mathrm{CrO}_{3}$ (the acid anhydride of chromic acid) is both much more soluble and more readily solubilized than $\mathrm{Cr}_{2} \mathrm{O}_{3}$, oxidation to $\mathrm{Cr}(\mathrm{VI})$ may lead to a higher corrosion rate than oxidation ending in $\mathrm{Cr}$ (III). In most test environments, the corrosion rate reflects the dissolution of $\mathrm{Cr}_{2} \mathrm{O}_{3}$ (or other $\mathrm{Cr}$ (III) oxides). As determined from electrochemical tests, the activation energy for this process is has a value of $25 \mathrm{~kJ} / \mathrm{mol}$. However, in environments sufficiently oxidizing to form $\mathrm{CrO}_{3}$, dissolution seems to occur by a different mechanism, which implies changes in the prefactor $R_{0}$ and the activation energy $E$.

To summarize the results of the autoclave studies, all environments tested yielded corrosion rates less than $0.25 \mu \mathrm{m} /$ year, even at $220^{\circ} \mathrm{C}$. The oxides that formed on the surfaces were predominately $\mathrm{Ni}(\mathrm{II})$ oxides consistent with $\mathrm{Ni}(\mathrm{OH})_{2}$. The oxides also contained chromium. Several samples showed evidence of stratification with a nickel oxide outer layer and a more chromium rich inner layer. For most samples, the chromium was predominately in the $3+$ oxidation state. In one of the environments $\left(\mathrm{NO}_{3} / \mathrm{Cl}=\right.$ 0.3125 ) where a $\mathrm{Cr}$ (III) oxide formed, the corrosion rate was measured over a temperature range of $120-220^{\circ} \mathrm{C}$. The activation energy was calculated to be $8 \pm 8$ $\mathrm{kJ} / \mathrm{mol}$, which is lower than the activation energy determined in electrochemical tests (25 $\mathrm{kJ} / \mathrm{mol}$ ). If all positive corrosion rates are used (ignoring the solution type), an activation energy of $10 \pm 3 \mathrm{~kJ} / \mathrm{mol}$ is obtained. The lower activation energies are more consistent with the LTCTF data, which showed corrosion rates with no temperature dependence. Under sufficiently oxidizing conditions, $\mathrm{Cr}_{2} \mathrm{O}_{3}$ converts to $\mathrm{CrO}_{3}$, which leads to a higher corrosion rate. The activation energy for this process was determined to be $49 \pm 25$ $\mathrm{kJ} / \mathrm{mol}$. More data points would be required to reduce the associated (high) uncertainty.

\section{Corrosion Rates in Crevice Solutions}

The high corrosion resistance of Alloy 22 over a broad range of environments is attributed to the passive film that develops at the metal interface. As established above, the oxide remains protective even at high temperatures and at high ionic strengths. However, the oxide film will dissolve in sufficiently aggressive environments. In occluded regions such as crevices and pits, it is possible for chemistries to evolve that are not in equilibrium with the outside environment. Metal hydrolysis reactions within the crevice can result in low $\mathrm{pH}$ solutions that can evolve at the same time that oxygen is depleted due to limited diffusion through the thin solution layers leading into the occluded regions. Whether the oxide fails under these low-pH and low-oxygen conditions depends on the temperature, the $\mathrm{pH}$, and the relative concentrations of corrosion promoters (such as chloride) to inhibitors (such as nitrate or sulfate).

To determine the limits of passive film stability in acidic conditions mimicking crevices, we have measured corrosion rates (as determined by polarization resistance) at 60 and $90^{\circ} \mathrm{C}$, on a coarse ionic strength grid $(1 \mathrm{~m}, 4 \mathrm{~m} \mathrm{NaCl})$, a coarse $\mathrm{NO}_{3} / \mathrm{Cl}$ ratio grid $(0.005,0.05,0.2,0.5)$, and a fine acid concentration scale (hydrochloric, sulfuric, oxalic, nitric). Hydrochloric, nitric and sulfuric acids are possible from the in-drift chemistry (note: certain exclusions and limitations imposed by detailed environmental analyses are not considered here), and oxalic and sulfuric acids are potential by-products of microbial 
activity. The nitrate/chloride ratios in this work were chosen to span below and above the value (0.2) where inhibition is seen in creviced specimens. Two salt concentrations were chosen to test whether breakdown is a sensitive function of chloride concentration. The results of the autoclave experiments suggesting that very high nitrate/chloride ratios (e.g., 6.7) can lead to less stability of the protective oxide films were not anticipated when the test matrix was designed. Thus, the highest ratio tested was 0.5 . The tests described here use an automated titration system that steps through solution conditions, measuring the open circuit potential (OCP) and the polarization resistance, and performing impedance spectroscopy measurements. In this report, we summarize the OCP and corrosion rate data (as derived from the polarization resistance).

The information obtained establishes the conditions of $\mathrm{pH}$ and solution composition under which Alloy 22 dissolution is sustainable. In other words, the data establish the "critical crevice solution chemistry" for localized corrosion. If a crevice can evolve to and sustain critical crevice solution chemistry, then the specimen will experience continued crevice corrosion. Conversely, if the environment is not sustainable, crevice corrosion will stop. The data also elucidate the inhibiting effect of nitrate and sulfate by correlating corrosion rate with OCP and surface morphology. In particular, this data set suggests that nitrate is very oxidizing under low $\mathrm{pH}$ conditions; this may promote a stable oxide film that inhibits localized corrosion.

\subsection{Connection to Crevice Corrosion Models}

Occluded environments are unavoidable on the waste package. Where they exist, it is possible for chemistries to evolve that are not in equilibrium with the bulk solution. In particular, the oxygen concentration (or partial pressure, $\mathrm{pO}_{2}$ ) is limited by diffusion through a thin solution layer and free oxygen can become depleted within the crevice region. This causes the electrical potential profile to develop due to the chemical differences between the inside and outside of the crevice. Once the potential drop spans the active-passive transition region, metal dissolution occurs and can initiate crevice corrosion (Xu and Pickering, 1993). Within the program, electrochemical testing of crevice specimens has established passive film failure as a function of external bulk solution concentrations, whereas the results shown here establish the limiting internal solutions. The results presented here are not directly comparable, but their relevance will be briefly summarized.

The empirical formula for determining breakdown is determined by the relative values of the OCP $\left(E_{\text {corr }}\right)$ and the critical potential $\left(E_{\text {crit }}\right)$. These values were determined for solutions in the range of $\mathrm{pH} 4$ to 12 . Within the model, corrosion initiates when $E_{\text {corr }} \geq E_{\text {crit }}$, where $E_{\text {crit }}$ is defined as the repassivation potential, $E_{\text {rcrev }}$. The OCP is a function of temperature $(T)$, solution $\mathrm{pH}$, chloride concentration, and when nitrate is present, the $\mathrm{NO}_{3} / \mathrm{Cl}$ ratio. A representation of the functional dependencies is given by:

$$
E_{\text {corr }}=c_{0}+c_{1} T+c_{2} p H+c_{3}[C l]+c_{4} \log \left[\mathrm{NO}_{3}\right] /[\mathrm{Cl}]
$$

Here $c_{0}=558 \pm 36 \mathrm{mV}, c_{1}=0.7 \pm 0.4 \mathrm{mV} / \mathrm{C}, c_{2}=-65 \pm 2 \mathrm{mV}, c_{3}=8 \pm 2 \mathrm{mV} / \mathrm{molal}$, and when nitrate is present, $c_{4}=37 \pm 2 \mathrm{mV}$; otherwise, the $c_{4}$ term is omitted. The critical crevice potential in the absence of nitrate is given by: 


$$
E_{\text {crev }}=E_{\text {Orcrev }}=a_{0}+a_{1} T+a_{2} p H+a_{3}[C l]+a_{4} \log [C l]
$$

Here $a_{0}=214 \pm 46 \mathrm{mV}, a_{1}=-3.7 \pm 0.5 \mathrm{mV} / \mathrm{C}, a_{2}=25 \pm 6 \mathrm{mV}, a_{3}=252 \pm 54 \mathrm{mV} / \mathrm{molal}$, and $a_{4}=1.4 \pm 0.5 \mathrm{mV}$. When nitrate is present $E_{\text {crev }}=E_{0 \text { crev }}-\Delta E_{\text {crev }}^{\mathrm{NO}_{3}}$ where $\Delta E_{\text {crev }}^{\mathrm{NO}_{3}}$ is given by:

$$
\Delta E_{\text {crev }}^{\mathrm{NO}_{3}}=b_{0}+b_{1}\left[\mathrm{NO}_{3}\right]+b_{2} \log \left[\mathrm{NO}_{3}\right] /[\mathrm{Cl}]
$$

Here the coefficients have the following values; $b_{0}=23 \pm 24, b_{1}=34 \pm 5$, and $b_{2}=750 \pm 95$. In Equations 5-7, concentration is in molality $\left(\mathrm{mol} / \mathrm{kg} \mathrm{H}_{2} \mathrm{O}\right)$ and temperature is in Celsius (BSC, 2004a).

The OCP obtained in the current data set can be directly compared to the predicted values for $E_{\text {corr }}$, although the present titration data have much lower $\mathrm{pH}$ values than those used to calculate the empirical coefficients. It will also be shown that sufficiently high $\mathrm{NO}_{3} / \mathrm{Cl}$ ratios suppress an active-passive response and can used to understand the inhibition of crevice corrosion in the context of the Pickering model.

\subsection{Methods: Titration Experiments}

We have developed a new titration method to test Alloy 22 passive film breakdown as a function of chloride, nitrate, sulfate, and oxalate concentrations over a wide range of acidity at 60 and $90^{\circ} \mathrm{C}$. The technique is illustrated in Figure 16.

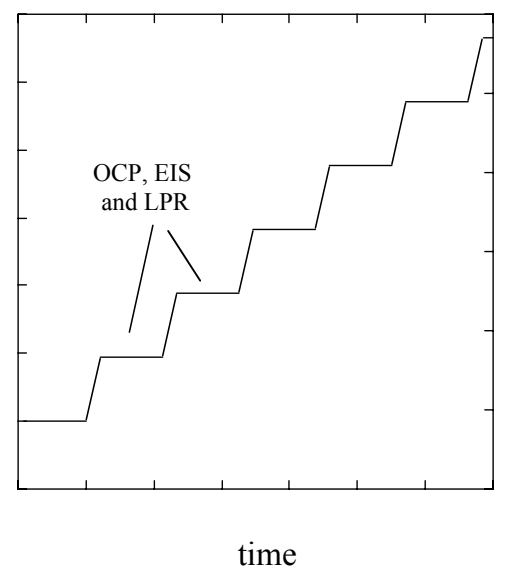

Note: During the periods of constant acid concentration, open circuit potential (OCP), electrochemical impedance spectroscopy (EIS), and linear polarization resistance (LPR) measurements are performed to characterize the corrosion properties of the alloy.

Figure 16. Schematic of acid concentration as a function of time for a representative titration experiment. 
Initially, the Alloy 22 sample is immersed in a de-aerated, 1-liter electrochemical cell filled with either $1 \mathrm{~m}$ or $4 \mathrm{~m}$ sodium chloride. The initial $\mathrm{pH}$ varies in practice from 4-6. An OCP measurement is performed for 1.5 hours to condition the sample surface with the solution. This appears to be a sufficient conditioning period, because 3-day measurements show very little change from values obtained after the first hour in acidic conditions. This wait time may be insufficient under neutral conditions; thus, the OCP values for the first couple of data points in the titrations may be underestimated. Following the OCP measurement, electrochemical impedance spectroscopy (EIS) and three consecutive linear polarization resistance (LPR) measurements are used to characterize the corrosion rate. Upon completion of the LPR measurements, a programmable dual-syringe pump is used to withdraw a precise volume of solution from the electrochemical cell and subsequently dispense a well-defined volume of acid (from an external reservoir) into the cell. In addition to acid, the external reservoir contains an equal amount of sodium chloride as the initial cell volume. Consequently, the amount of sodium chloride in the cell remains constant, while the overall acid concentration increases. Once the syringe pump dispenses acid into the cell, an OCP measurement is again performed followed by LPR. This process is repeated many times until the $\mathrm{pH}$ is well below zero.

Hydrochloric, sulfuric, and nitric acid titrations were all performed in constant sodium chloride solutions of $1 \mathrm{~m}$ and $4 \mathrm{~m}$, while oxalic acid titration was performed in $0.125 \mathrm{~m}$ sodium chloride $(\mathrm{NaCl})$, due to precipitation observed at higher $\mathrm{NaCl}$ concentrations. The chloride concentration remains fixed throughout the titration for pure sulfuric, oxalic, and nitric acid titrations. However, the total chloride concentration varies when $\mathrm{HCl}$ is one of the titrants or when various $\mathrm{NO}_{3} / \mathrm{Cl}$ and $\mathrm{SO}_{4} / \mathrm{Cl}$ ratios are being maintained. The test matrix and corresponding sample identification are shown in Table 7.

\subsection{The Effect of Acid Type on Corrosion}

In this section, we compare the critical acid concentrations that lead to the breakdown of the passive oxide film on Alloy 22 in hydrochloric $(\mathrm{HCl})$, sulfuric $\left(\mathrm{H}_{2} \mathrm{SO}_{4}\right)$, nitric $\left(\mathrm{HNO}_{3}\right)$, and oxalic $\left(\mathrm{H}_{2} \mathrm{C}_{2} \mathrm{O}_{4}\right)$ acids in sodium chloride $(\mathrm{NaCl})$ containing environments at 60 and $90^{\circ} \mathrm{C}$.

\subsubsection{Results and Discussion}

Figures 17 and 18 compare corrosion rates and OCP values as a function of the negative logarithm of the hydrogen concentration for the different acids at $90^{\circ} \mathrm{C}$ in a $1 \mathrm{~m}$ $\mathrm{NaCl}$ base, $60^{\circ} \mathrm{C}$ in a $1 \mathrm{~m} \mathrm{NaCl}$ base, and $90^{\circ} \mathrm{C}$ in a $4 \mathrm{~m} \mathrm{NaCl}$ base. For the purposes of these graphs, the acids are assumed to completely dissociate and the acidity or effective " $\mathrm{pH}$ " is reported as the negative logarithm of the stoichiometric molality of the hydrogen ion solute component $[-\log \mathrm{m}(\mathrm{H}, \mathrm{St})]$. This is a good assumption for hydrochloric and nitric acids because these are strong acids, but it is invalid for sulfuric and oxalic acids at relatively low $\mathrm{pH}$. Moreover, the plots assume that sulfuric and oxalic acids contain two dissociated hydrogen ions. The true correspondence between acid concentrations and $\mathrm{pH}$, 
which is a function of the hydrogen ion activity rather than concentration, requires geochemical modeling (which was outside the scope of this work).

Table 7. Test matrix for the titration experiments

\begin{tabular}{|c|c|c|c|c|c|}
\hline Sample ID & $T\left({ }^{\circ} \mathrm{C}\right)$ & Initial $\mathrm{NaCl}^{(1)}$ & Acid & $\mathrm{NO}_{3} / \mathrm{Cl}$ & $\mathrm{SO}_{4} / \mathrm{Cl}$ \\
\hline DEA1114 & 60 & 1 & $\mathrm{HCl}$ & 0 & 0 \\
\hline DEA661 & 60 & 1 & $\mathrm{H}_{2} \mathrm{SO}_{4}$ & 0 & varies \\
\hline DEA577 & 50 & 1 & Oxalic & 0 & 0 \\
\hline DEA1121 & 90 & 1 & $\mathrm{HCl}$ & 0 & 0 \\
\hline DEA1139 & 90 & 1 & $\mathrm{HNO}_{3}$ & varies & 0 \\
\hline DEA1062 & 90 & 1 & $\mathrm{H}_{2} \mathrm{SO}_{4}$ & 0 & varies \\
\hline DEA1059 & 90 & 1 & Oxalic & 0 & 0 \\
\hline DEA671 & 90 & 4 & $\mathrm{HCl}$ & 0 & 0 \\
\hline DEA679 & 90 & 4 & $\mathrm{HNO}_{3}$ & varies & 0 \\
\hline DEA678 & 90 & 4 & $\mathrm{H}_{2} \mathrm{SO}_{4}$ & 0 & varies \\
\hline DEA662 & 60 & 1 & $0.05 \mathrm{NO}_{3} / \mathrm{Cl}$ & 0.05 & 0 \\
\hline DEA663 & 60 & 1 & $0.2 \mathrm{NO}_{3} / \mathrm{Cl}$ & 0.2 & 0 \\
\hline DEA660 & 60 & 1 & $0.5 \mathrm{NO}_{3} / \mathrm{Cl}$ & 0.5 & 0 \\
\hline DEA1113 & 90 & 1 & $0.005 \mathrm{NO}_{3} / \mathrm{Cl}$ & 0.005 & 0 \\
\hline DEA1125 & 90 & 1 & $0.05 \mathrm{NO}_{3} / \mathrm{Cl}$ & 0.05 & 0 \\
\hline DEA1124 & 90 & 1 & $0.2 \mathrm{NO}_{3} / \mathrm{Cl}$ & 0.2 & 0 \\
\hline DEA514 & 90 & 1 & $0.5 \mathrm{NO}_{3} / \mathrm{Cl}$ & 0.5 & 0 \\
\hline DEA677 & 90 & 4 & $0.05 \mathrm{NO}_{3} / \mathrm{Cl}$ & 0.05 & 0 \\
\hline DEA676 & 90 & 4 & $0.2 \mathrm{NO}_{3} / \mathrm{Cl}$ & 0.2 & 0 \\
\hline DEA670 & 90 & 4 & $0.5 \mathrm{NO}_{3} / \mathrm{Cl}$ & 0.5 & 0 \\
\hline DEA668 & 60 & 1 & $0.1 \mathrm{SO}_{4} / \mathrm{Cl}$ & 0 & 0.1 \\
\hline DEA688 & 60 & 1 & $0.5 \mathrm{SO}_{4} / \mathrm{Cl}$ & 0 & 0.5 \\
\hline DEA669 & 60 & 1 & $1 \mathrm{SO}_{4} / \mathrm{Cl}$ & 0 & 1 \\
\hline DEA664 & 90 & 1 & $0.1 \mathrm{SO}_{4} / \mathrm{Cl}$ & 0 & 0.1 \\
\hline DEA682 & 90 & 1 & $0.5 \mathrm{SO}_{4} / \mathrm{Cl}$ & 0 & 0.5 \\
\hline DEA665 & 90 & 1 & $1 \mathrm{SO}_{4} / \mathrm{Cl}$ & 0 & 1 \\
\hline
\end{tabular}

${ }^{1}$ This is the molality. The value in each case remains fixed throughout the titration for pure sulfuric, oxalic, and nitric titrations. However, the chloride concentration varies when $\mathrm{HCl}$ is one of the titrants as for $\mathrm{HCl}$ and the various $\mathrm{NO}_{3} / \mathrm{Cl}$ and $\mathrm{SO}_{4} / \mathrm{Cl}$ ratios.

Note: Samples held at 50 or $60^{\circ} \mathrm{C}$ are shown with a gray background.

The $\mathrm{pH}$ value where the corrosion rate rapidly increases marks the breakdown of the passive film of Alloy 22 and is the critical environment that leads to rapid corrosion. In this report, we define the critical environment as the hydrogen concentration where the corrosion rate exceeds $\sim 10 \mu \mathrm{m} /$ year. In hydrochloric and sulfuric acid, the critical $\mathrm{pH}$ values at $90^{\circ} \mathrm{C}$ in $1 \mathrm{~m} \mathrm{NaCl}$ are 1 and 0.25 , respectively. In more concentrated $4 \mathrm{~m}$ salt solutions (Figure 18), these both shift to higher values: 1.5 and 2 for hydrochloric and sulfuric acid, respectively. The breakdown of the passive film is also reflected in the OCP 
curves where the OCP decreases at the onset of corrosion. No significant corrosion occurs for nitric acid. In the low $\mathrm{pH}$ range, where the other acid solutions broke down the oxide film, the OCP steadily increases. Together, these suggest that nitric acid acts as an oxidizer, which perfects the oxide film and raises the OCP into the passive region. Oxalic acid shows significant corrosion rates at a $\mathrm{pH}$ of 0.5 , but the passive film does not completely break down as indicated by the lower corrosion rates and the higher OCP at low $\mathrm{pH}$.

(a)

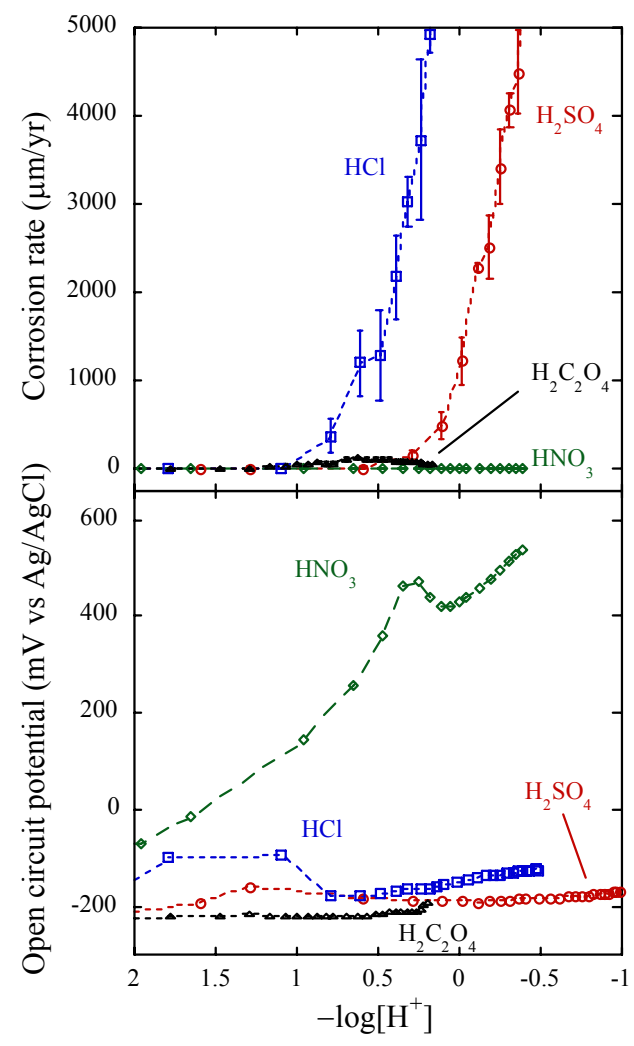

(b)

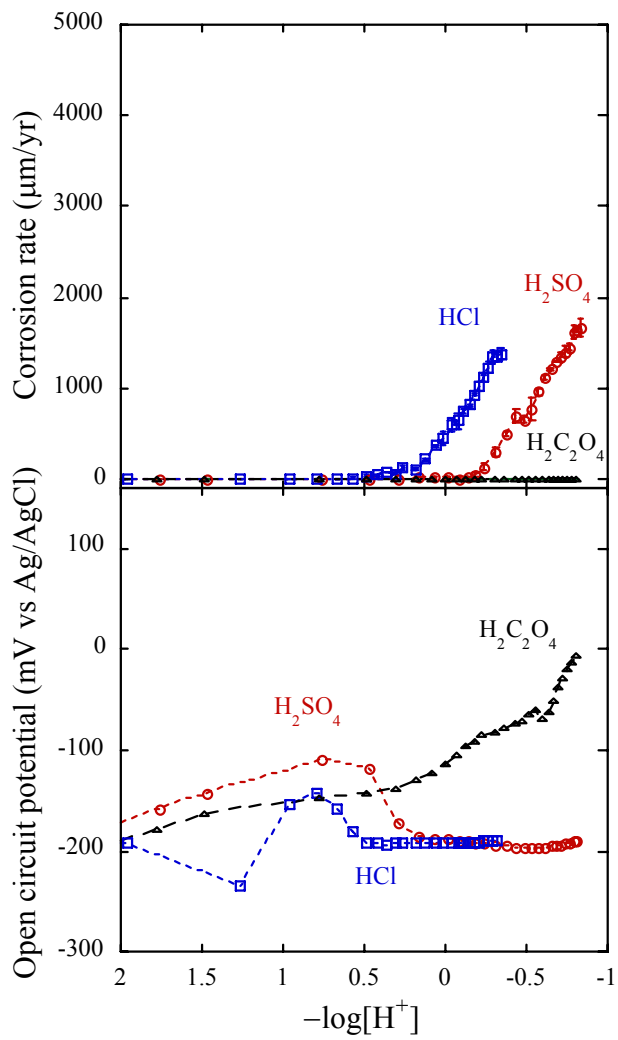

Source: Hayes, 2004b.

Figure 17. Corrosion rates (top) and OCP (bottom) vs. $-\log \left[\mathrm{H}^{+}\right](\mathrm{pH})$ for hydrochloric $(\mathrm{HCl})$, sulfuric $\left(\mathrm{H}_{2} \mathrm{SO}_{4}\right)$, nitric $\left(\mathrm{HNO}_{3}\right)$, and oxalic $\left(\mathrm{H}_{2} \mathrm{C}_{2} \mathrm{O}_{4}\right)$ acids at (a) $90^{\circ} \mathrm{C}$ and (b) $60^{\circ} \mathrm{C}$. 


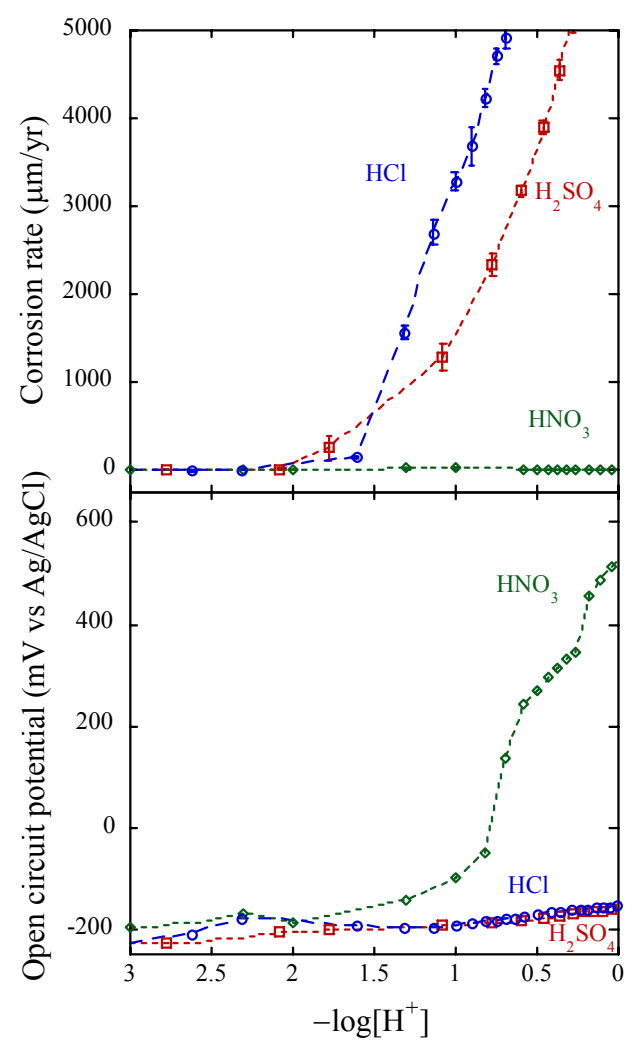

Source: Hayes, 2004b.

Figure 18. Corrosion rates (top) and OCP (bottom) vs. $-\log \left[\mathrm{H}^{+}\right]$for $\mathrm{HCl}$, $\mathrm{H}_{2} \mathrm{SO}_{4}$, and $\mathrm{HNO}_{3}$ acids at $90^{\circ} \mathrm{C}$ in $4 \mathrm{~m}$ $\mathrm{NaCl}$.

The onset of crevice corrosion is strongly dependent on solution composition and is not solely a function of the acidity of the solution. The titration experiments show that nitrate in chloride solutions strongly inhibits corrosion as compared to pure chloride and chloride plus sulfate solutions. Note that nitric acid titrations were not performed at $60^{\circ} \mathrm{C}$ because no significant corrosion occurred at $90^{\circ} \mathrm{C}$. Dissolved sulfate also appears to inhibit the corrosion, as is illustrated by the lower $-\log \left[\mathrm{H}^{+}\right]$values that are required to break down the passive film, as compared to results for the pure chloride solutions. The ability of sulfate to protect the passive film is likely less than is suggested here, because preliminary geochemical calculations (not shown) indicate that $-\log \left[\mathrm{H}^{+}\right]$required for passive film breakdown is about 0.45 units higher than shown in Figures 17 and 18. Oxalate plus chloride also appears to inhibit corrosion rates compared to pure chloride. However, the lower corrosion rates may be due to the 10 times lower chloride concentrations in the oxalic acid experiments than in the sulfuric and nitric acid titration experiments.

Atomic force microscope images of the surface morphology following titration experiments (Figure 19) clearly indicate that the mode of metal dissolution differs in the 
different acid types. Samples exposed to titrations in hydrochloric and oxalic acids demonstrate similar modes of corrosion attack, in which preferential etching occurs depending on the orientation of the grain. Nitric acid titrations lead to mild intergranular attack, and sulfuric acid environments show preferential etching at step edges. The micrographs indicate that specific atomic sites on the metal surface have higher dissolution rates than others in these acid environments. Overall, this leads to a roughening of the surfaces. In particular, preferential grain etching (seen with hydrochloric and oxalic acids) leads to large depressed regions, suggestive of shallow pits 200-500 nm deep and tens of micrometers wide, whereas intergranular etching (observed with nitric acid) leads to thin narrow crevices. In some environments, these geometries may be sufficiently occluded to allow chemical perturbations that initiate localized corrosion. For example, the higher corrosion rates at the grain boundaries observed in nitric acid may be caused when nitrate, which is consumed during metal oxidation, is not replenished within the crevice due to geometrical constraints on diffusive transfer.

The morphology observed in the case of sulfuric acid is suggestive of a steppinning mechanism that leads to slower dissolution of specific step orientations. Each of the metal grains in the image has fluctuating steps that are approximately aligned in one orientation. Moreover, the steps have a scalloped appearance that often occurs when adsorbates impede the local motion of the step, eventually leading to the bunching of steps. Steps that do not have the proper chemistry, shape, or size to allow adsorbate binding will move (dissolve) unimpeded, resulting in a morphology that is dictated by the slower moving pinned steps. In the case of sulfuric acid, this suggests that step-specific sulfate binding plays a role in the inhibitory effect.

\subsection{The Corrosion-Inhibiting Effects of Nitrate and Sulfate on Alloy 22 in Acidic Environments}

We further investigated the inhibiting effects of nitrate and sulfate in crevice environments for $\mathrm{NO}_{3} / \mathrm{Cl}$ ratios of $0.005,0.05,0.2$ and 0.5 (Figures 20, 21, and 22) and for $\mathrm{SO}_{4} / \mathrm{Cl}$ ratios of 0.1 and 1 in sodium chloride solutions (Figure 23) at 60 and $90^{\circ} \mathrm{C}$ using the same titration method. The effect of higher salt concentrations is considered for the nitrate study $(1 \mathrm{~m}$ and $4 \mathrm{~m} \mathrm{NaCl})$. The goal of this research is to determine the critical $\mathrm{NO}_{3} / \mathrm{Cl}$ and $\mathrm{SO}_{4} / \mathrm{Cl}$ needed to maintain the passive film in a crevice environment and to understand the physical mechanism of the inhibition process and breakdown.

\subsubsection{Results and Discussion}

As summarized in Table 8, nitrate is a very effective inhibitor of localized corrosion. This is shown by the increased acidity required to break down the passive film in nitrate plus chloride solutions over that in pure chloride solutions (about 10 times more $\mathrm{H}^{+}$at 60 and $90^{\circ} \mathrm{C}$ in $1 \mathrm{~m} \mathrm{NaCl}$ solutions and 100 times more $\mathrm{H}^{+}$at $90^{\circ} \mathrm{C}$ in $4 \mathrm{~m}$ solutions). This implies that 10 to 100 times more hydrolysis of the metal is required to break down the passive film in the presence of nitrate. The ability of nitrate to stabilize the passive film also depends on the $\mathrm{NO}_{3} / \mathrm{Cl}$ ratio and the temperature. In the $90^{\circ} \mathrm{C} 1 \mathrm{~m}$ and $4 \mathrm{~m} \mathrm{NaCl}$ solutions with $\mathrm{NO}_{3} / \mathrm{Cl}=0.05$, there is a region reminiscent of an active passive transition where the corrosion rates increase and then decrease until the critical $-\log \left[\mathrm{H}^{+}\right]$value is 

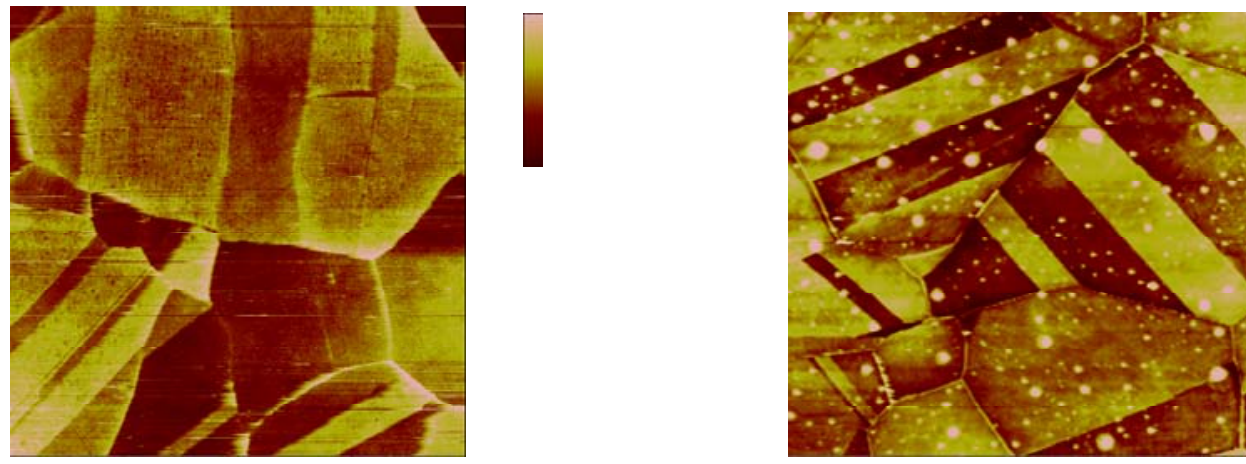

$100 \mu \mathrm{m}$
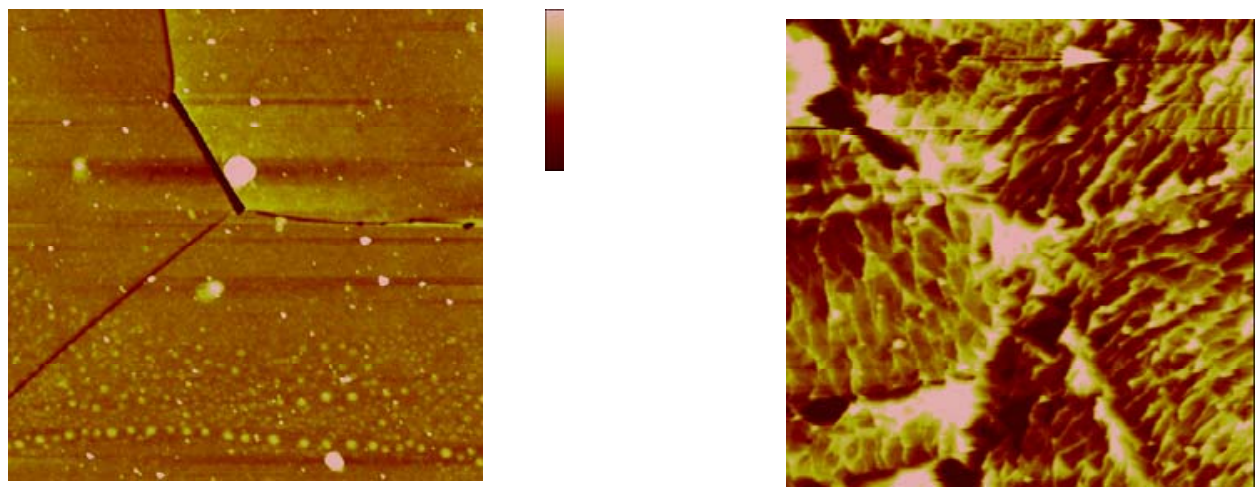

Source: Hayes, 2004a.

Note: The length of the edge is given below the image, and the $z$ scale is shown at the right. The individual metal grains etch at different rates in $\mathrm{HCl}$ and $\mathrm{H}_{2} \mathrm{C}_{2} \mathrm{O}_{4}$, resulting in a surface relief with the slowly etching metal grains upraised (light) relative to the faster etching grains (dark). In $\mathrm{HNO}_{3}$, the metal grains etch at similar rates, but the grain boundaries etch faster and are therefore dark. In $\mathrm{H}_{2} \mathrm{SO}_{4}$, the metal grains are more difficult to discern, but preferred step directions are apparent that change from grain to grain.

Figure 19. Atomic force microscopy (AFM) images of the surface morphology of Alloy 22 after titration experiments at $90^{\circ} \mathrm{C}$ in $1 \mathrm{~m} \mathrm{NaCl}$ for $\mathrm{HCl}_{2} \mathrm{H}_{2} \mathrm{SO}_{4}$, and $\mathrm{HNO}_{3}$ and $1 / 8$ molal $\mathrm{NaCl}$ for $\mathrm{H}_{2} \mathrm{C}_{2} \mathrm{O}_{4}$. 
reached. Presumably, this represents restabilization of the passive film even at these low $\mathrm{NO}_{3} / \mathrm{Cl}$ ratios. At lower salt concentration, this occurs even with ratios as low as 0.005 (Figure 22). The effect of $\mathrm{NO}_{3}$ on passive film stability appears to reach a plateau above $\mathrm{NO}_{3} / \mathrm{Cl}=0.2$, where higher ratios do not improve the performance of the passive film. Nitrate may be a more effective inhibitor of corrosion at lower temperatures, because we do not observe this transition in high to low corrosion rates at $\mathrm{NO}_{3} / \mathrm{Cl}=0.05$ at $60^{\circ} \mathrm{C}$. The positive correlation between $\mathrm{OCP}$ and the $\mathrm{NO}_{3} / \mathrm{Cl}$ ratio also supports the interpretation that nitrate oxidizes Alloy 22 and stabilizes the passive film (Figures 20 and 21).

Table 8. Critical environments for nitrate- and chloride-containing solutions: $-\log \mathrm{m}(\mathrm{H}, \mathrm{St})$ values sufficiently low to cause corrosion rates of $\sim 10 \mu \mathrm{m} /$ year.

\begin{tabular}{|l|l|l|l|l|l|}
\hline & \multicolumn{5}{|c|}{ Nitrate to Chloride Ratio } \\
\cline { 2 - 6 } & 0 & 0.005 & 0.05 & 0.2 & 0.5 \\
\hline $60^{\circ} \mathrm{C}, 1 \mathrm{~m} \mathrm{NaCl}$ & 0.6 & $\mathrm{NA}$ & -0.3 & -0.4 & -0.5 \\
\hline $90^{\circ} \mathrm{C}, 1 \mathrm{~m} \mathrm{NaCl}$ & 0.7 & $-0.2^{1}$ & $-0.4^{1}$ & -0.3 & -0.2 \\
\hline $90^{\circ} \mathrm{C}, 4 \mathrm{~m} \mathrm{NaCl}$ & 2.0 & $\mathrm{NA}$ & 0.1 & 0.2 & 0.0 \\
\hline
\end{tabular}

In the absence of nitrate, the OCP during hydrochloric titration is constant and negative, and the passive film breaks down at relatively high $\mathrm{pH}$ values $\left(-\log \left[\mathrm{H}^{+}\right]\right.$near 1 in $1 \mathrm{~m} \mathrm{NaCl}$ and near 2 in $4 \mathrm{~m} \mathrm{NaCl}$ at $\left.90^{\circ} \mathrm{C}\right)$. By contrast, with a little nitrate $\left(\mathrm{NO}_{3} / \mathrm{Cl}=\right.$ $0.5)$, the OCP is slightly higher than in pure hydrochloric acid until the oxide film has repassivated, but then it rapidly approaches the much higher values of a pure nitrate system. At the same time, the corrosion rates drop to a minimal level. The relationship between OCP and corrosion rate is further demonstrated in Figure 22. For all ratios of $\mathrm{NO}_{3} / \mathrm{Cl}$, the OCP rises with increasing acid concentration. Consequently, the alloy passes through a region reminiscent of an active to passive transition at approximately $0 \mathrm{mV}$ versus $\mathrm{Ag} / \mathrm{AgCl}$. In this region, the peak corrosion rates are a sensitive function of the $\mathrm{NO}_{3} / \mathrm{Cl}$ ratio, decaying exponentially as the ratio increases (Figure 22b). Once the acid concentration increases to a critical value $\left(500 \mathrm{mV}\right.$ for $\mathrm{NO}_{3} / \mathrm{Cl}=0.5,300 \mathrm{mV}$ for $\mathrm{NO}_{3} / \mathrm{Cl}$ $=0.05$, and $200 \mathrm{mV}$ for $\mathrm{NO}_{3} / \mathrm{Cl}=0.005$ ), a transpassive-like corrosion rate dominates. Higher nitrate/chloride ratios shift this transpassive behavior to higher potentials following a power law, with the breakdown potential increasing as the ratio raised to the power 0.3 (Figure 22c). 
(a)

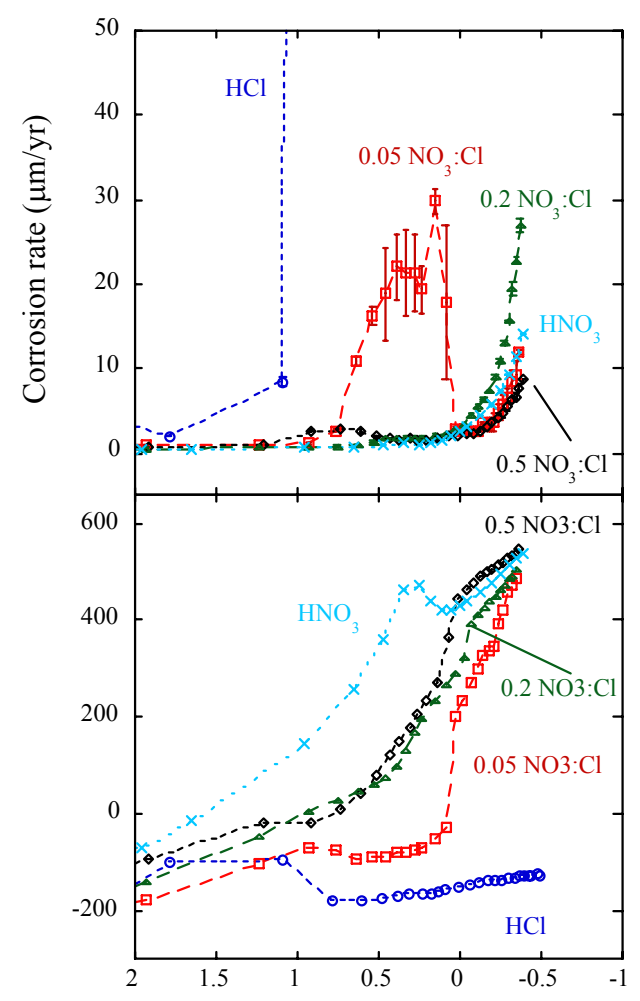

(b)

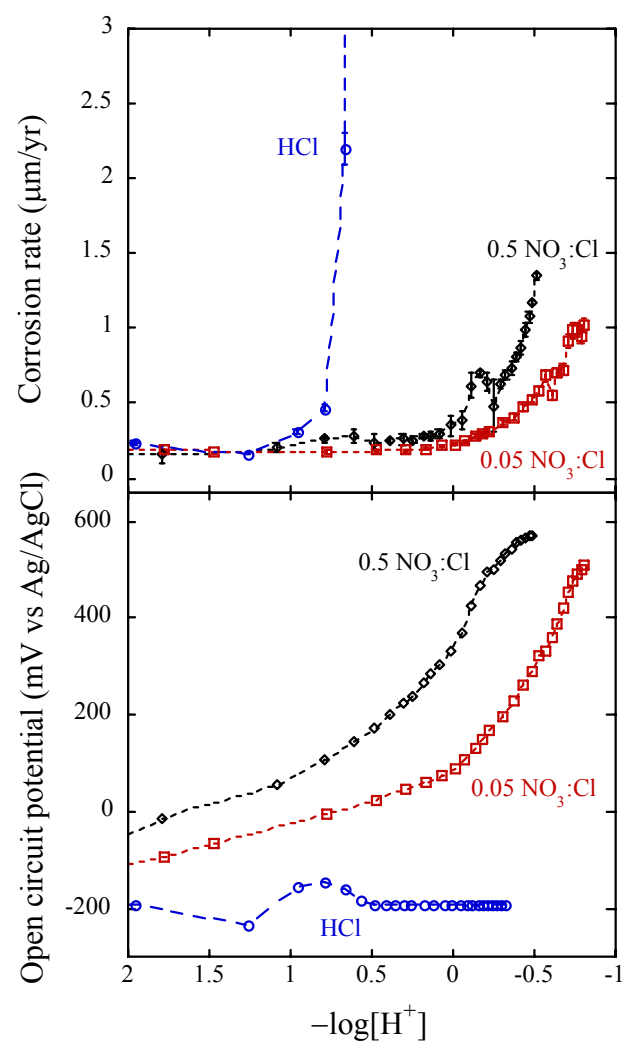

Source: Hayes, 2004b.

Figure 20. Corrosion rates (top) and OCP (bottom) vs. $-\log \left[\mathrm{H}^{+}\right](\mathrm{pH})$ for hydrochloric $(\mathrm{HCl})$ and nitric $\left(\mathrm{HNO}_{3}\right)$ acids and ratios of $\mathrm{NO}_{3} / \mathrm{Cl}$ of (a) $0.5,0.2$, and 0.05 at $90^{\circ} \mathrm{C}$ and (b) 0.5 and 0.05 at $60^{\circ} \mathrm{C}$. 


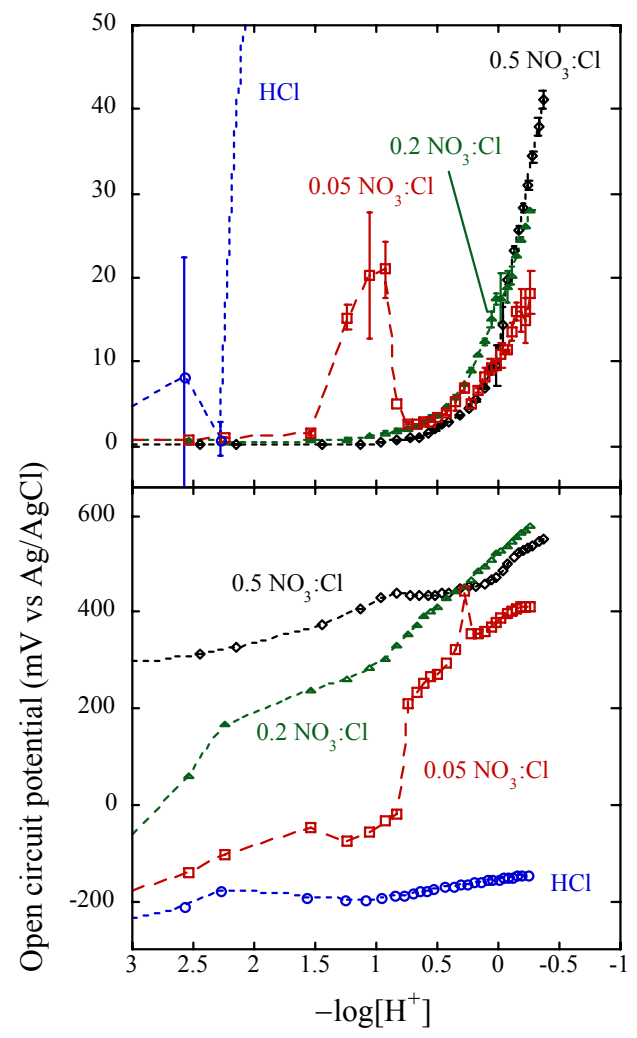

Source: Hayes, 2004b.

Figure 21. Corrosion rates (top) and OCP (bottom) vs. $-\log \left[\mathrm{H}^{+}\right](\mathrm{pH}) \mathrm{HCl}$ and ratios of $\mathrm{NO}_{3} / \mathrm{Cl}$ of $0.5,0.2$, and 0.05 at $90^{\circ} \mathrm{C}$ in an initial base of $4 \mathrm{~m} \mathrm{NaCl}$.

From Figure 22, the critical $\mathrm{NO}_{3} / \mathrm{Cl}$ ratio for significant corrosion rates (and consequently crevice corrosion) in $1 \mathrm{~m} \mathrm{NaCl}$ at $90^{\circ} \mathrm{C}$ is between 0.05 and 0.5 . This compares well with tests done at LLNL on actual crevice specimens, which found that ratios greater than 0.2 do not crevice corrode. At $60^{\circ} \mathrm{C}$, the corrosion rates are extremely low, and the OCP values increase rapidly to the passive region. Consequently, no critical crevice ratio exists at $60^{\circ} \mathrm{C}$ for the ratios tested. 
(a)

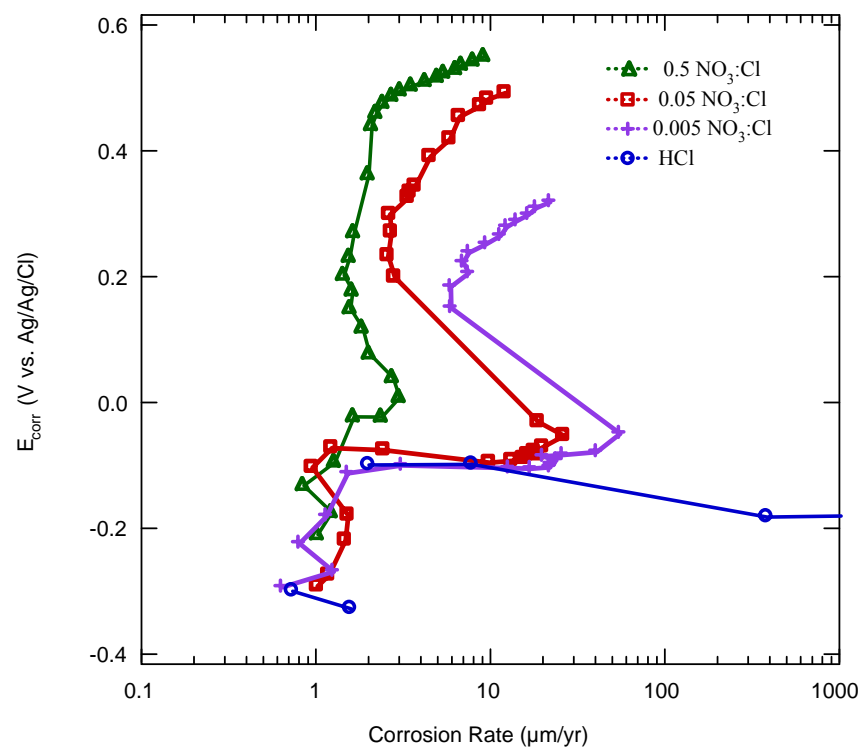

(b)

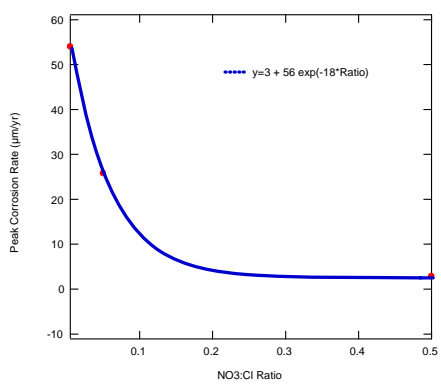

(c)

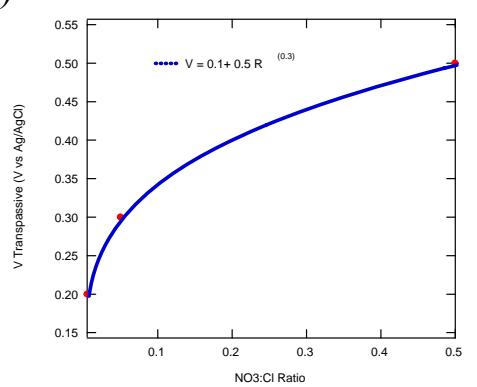

Source: Hayes, 2004b.

Note: Two points (-0.024 V, $17.2 \mu \mathrm{m} /$ year; $-0.026 \mathrm{~V}, 3.9 \mu \mathrm{m} /$ year) were removed from the $0.005 \mathrm{NO}_{3} / \mathrm{Cl}$ curve in (a) so that the curves did not overlap as much. In (b), the peak corrosion rate versus the $\mathrm{NO}_{3} / \mathrm{Cl}$ ratio can be fit with an exponential function, peak corrosion rate $=3+\exp \left(-18^{\star}\right.$ Ratio). In (c), the breakdown potential where transpassive dissolution occurs has a power law dependence on the nitrate to chloride ratio, $V_{\text {trans }}=0.1+0.5^{\star} \operatorname{Ratio}^{(0.3)}$.

Figure 22. Corrosion rates vs. OCP for $\mathrm{HCl}$ and ratios of $\mathrm{NO}_{3} / \mathrm{Cl}$ of $0.5,0.05$, and 0.005 during acid titration experiments at $90^{\circ} \mathrm{C}$ with initial salt concentration of $1 \mathrm{~m} \mathrm{NaCl}$.

The corrosion inhibition effect of sulfate is much more subtle than that of nitrate. The effect is an overall shift in the critical $-\log \left[\mathrm{H}^{+}\right]$for passive film breakdown (Figure 23). In $1 \mathrm{~m} \mathrm{NaCl}$ at $90^{\circ} \mathrm{C}$, the critical $-\log \left[\mathrm{H}^{+}\right]$for breakdown shifts from a value of 1 for $\mathrm{HCl}$ to about 0.4 for $\mathrm{SO}_{4} / \mathrm{Cl}=0.1$ and 1 at $90^{\circ} \mathrm{C}$ and about 0.4 for $\mathrm{SO}_{4} / \mathrm{Cl}=0.1$ and 0.0 for $\mathrm{SO}_{4} / \mathrm{Cl}=1$ at $60^{\circ} \mathrm{C}$. Critical $-\log \left[\mathrm{H}^{+}\right]$values for all $\mathrm{SO}_{4}$ ratios in the tested environments are summarized in Table 9. Correcting the plots for the dissociation of sulfuric acid would increase the critical $-\log \left[\mathrm{H}^{+}\right]$to a value near 0.65 at $90^{\circ} \mathrm{C}$ and 0.65 to 0.25 at $60^{\circ} \mathrm{C}$ for sulfate-containing $\mathrm{NaCl}$ brines (see above), indicating a very small effect of $\mathrm{SO}_{4}$ on localized corrosion. Thus, sulfate does not appear to oxidize Alloy 22 and preserve the passive film, as nitrate does. This conclusion is supported by the negative OCP values for the sulfate plus chloride solutions. 
(a)

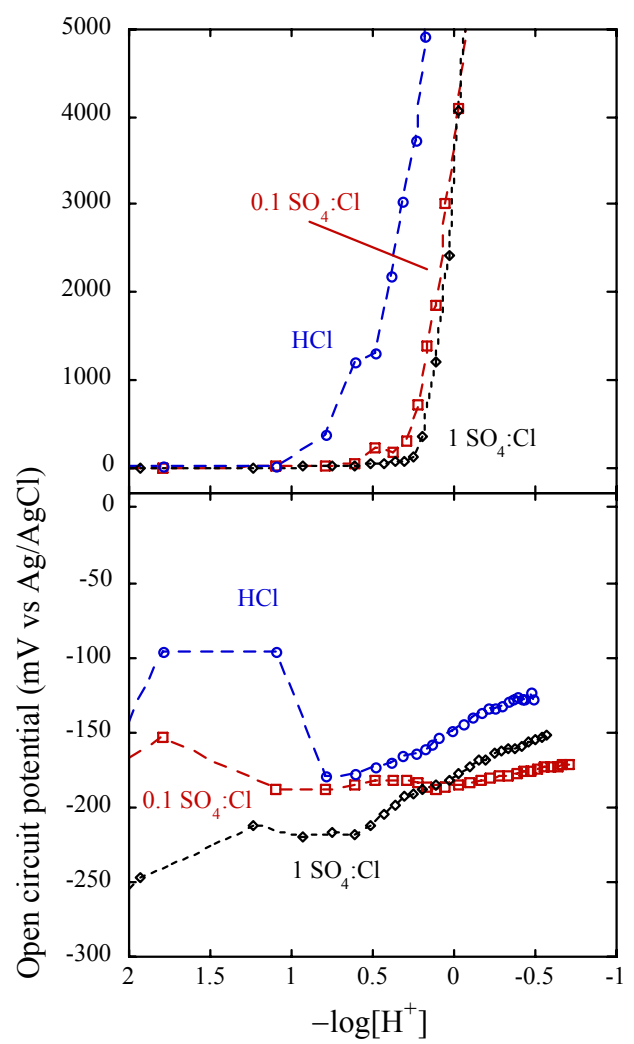

(b)

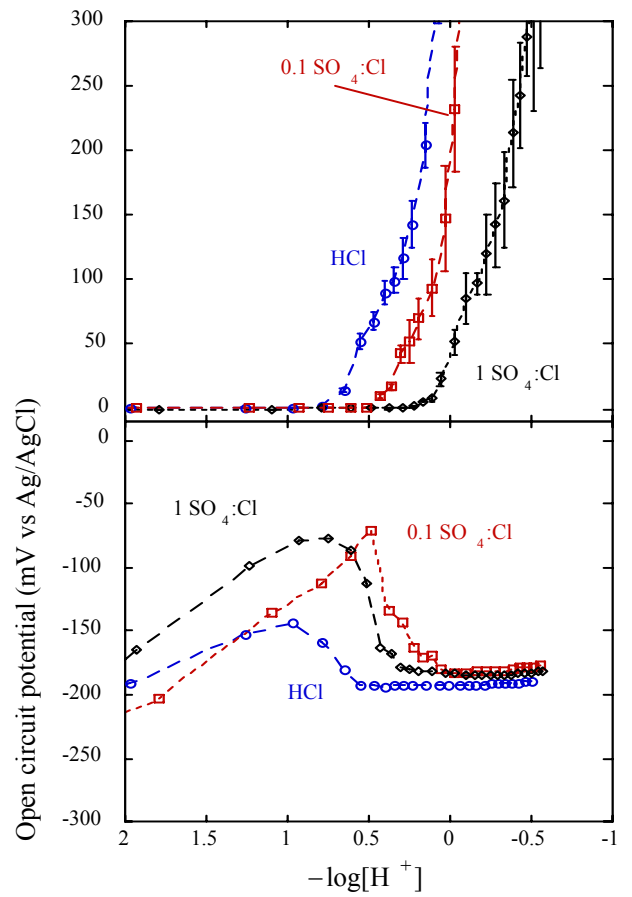

Source: Hayes, 2004b.

Figure 23. Corrosion rates (top) and OCP (bottom) vs. $-\log \left[\mathrm{H}^{+}\right](\mathrm{pH}) \mathrm{HCl}$ and ratios of $\mathrm{SO}_{4} / \mathrm{Cl}$ of 1 and 0.1 . in $1 \mathrm{~m} \mathrm{NaCl}$ at (a) $90^{\circ} \mathrm{C}$ and (b) $60^{\circ} \mathrm{C}$.

Table 9. Critical $-\log \left[\mathrm{H}^{+}\right]$values for passive film breakdown for $\mathrm{SO}_{4} / \mathrm{Cl}$ ratios of $1: 1$ at $60^{\circ} \mathrm{C}$ and $1: 10$ at $90^{\circ} \mathrm{C}$.

\begin{tabular}{|l|c|c|}
\hline & $\begin{array}{c}\text { Critical }-\log \left[\mathrm{H}^{+}\right] \text {in } \\
\mathbf{1 m ~ N a C l} \text { at } \mathbf{9 0}^{\circ} \mathbf{C}\end{array}$ & $\begin{array}{c}\text { Critical }-\log \left[\mathrm{H}^{+}\right] \text {in } \\
\mathbf{1 m ~ N a C l} \text { at } 60^{\circ} \mathbf{C}\end{array}$ \\
\hline Hydrochloric $(\mathrm{HCl})$ & 1.0 & 0.75 \\
\hline $1: 10 \mathrm{SO}_{4} / \mathrm{Cl}$ & 0.4 & 0.4 \\
\hline $1: 1 \mathrm{SO}_{4} / \mathrm{Cl}$ & 0.38 & 0.0 \\
\hline
\end{tabular}

\subsection{Implications to Alloy 22 Corrosion at Yucca Mountain}

In summary, the breakdown of the passive film of Alloy 22 occurs for $\mathrm{HCl}$ and $\mathrm{H}_{2} \mathrm{SO}_{4}$ in all environments tested, and the critical $\mathrm{pH}$ for breakdown is a function of the temperature and molality of $\mathrm{NaCl}$ (Table 10). Oxalic acid begins to break down the passive film at $90^{\circ} \mathrm{C}$ but shows very little corrosion at $50^{\circ} \mathrm{C}$ where by-products of 
microbial activity might be expected. The chloride concentration used in this study is only $0.125 \mathrm{~m}$, which corresponds to very dilute seepage water that has undergone a minimal amount of evaporation. In more concentrated brines, $\mathrm{NaCl}$ will precipitate out of solution due to its low solubility in oxalic acid. The data show that no corrosion is expected from oxalic acid under repository conditions. Nitric acid does not break down the passive film of Alloy 22 in any of the tested environments.

Table 10. Summary of critical environments

\begin{tabular}{|c|c|c|c|c|}
\hline Acid & $\begin{array}{c}\text { Critical }-\log \left[\mathrm{H}^{+}\right] \text {in } \\
1 \mathrm{~m} \mathrm{NaCl} \text { at } 90^{\circ} \mathrm{C}\end{array}$ & $\begin{array}{c}\text { Critical }-\log \left[\mathrm{H}^{+}\right] \text {in } \\
4 \mathrm{~m} \mathrm{NaCl} \text { at } 90^{\circ} \mathrm{C}\end{array}$ & $\begin{array}{c}\text { Critical }-\log \left[\mathrm{H}^{+}\right] \text {in } \\
1 \mathrm{~m} \mathrm{NaCl} \text { at } 60^{\circ} \mathrm{C}\end{array}$ & $\begin{array}{c}\text { Mechanism of } \\
\text { breakdown }\end{array}$ \\
\hline $\begin{array}{l}\text { Hydrochloric } \\
(\mathrm{HCl})\end{array}$ & 1.0 & 1.5 & 0.0 & $\begin{array}{l}\text { Preferential grain } \\
\text { etching }\end{array}$ \\
\hline $\begin{array}{l}\text { Sulfuric } \\
\left(\mathrm{H}_{2} \mathrm{SO}_{4}\right)\end{array}$ & $\left.0.25+(0.3)^{1}+0.15\right)^{2}$ & $2.0+(0.3)^{1}+(0.15)^{2}$ & $\begin{array}{l}-0.25+(0.3)^{1} \\
+(0.15)^{2}\end{array}$ & $\begin{array}{l}\text { Preferential step } \\
\text { etching }\end{array}$ \\
\hline Nitric $\left(\mathrm{HNO}_{3}\right)$ & No film breakdown & No film breakdown & No film breakdown & $\begin{array}{l}\text { Mild intergranular } \\
\text { attack }\end{array}$ \\
\hline $\begin{array}{c}\text { Oxalic } \\
\left(\mathrm{H}_{2} \mathrm{C}_{2} \mathrm{O}_{4}\right)\end{array}$ & $0.5^{3}+(0.3)^{1}$ & $\mathrm{~N} / \mathrm{A}$ & No film breakdown ${ }^{3,4}$ & $\begin{array}{l}\text { Preferential grain } \\
\text { etching }\end{array}$ \\
\hline
\end{tabular}

${ }^{1}$ Correction to account for the fact that $\mathrm{H}_{2} \mathrm{SO}_{4}$ and $\mathrm{H}_{2} \mathrm{C}_{2} \mathrm{O}_{4}$ do not dissociate into two free hydrogen ions but rather more closely yield only one.

${ }^{2}$ This is an approximate correction to account for the fact that $\mathrm{H}_{2} \mathrm{SO}_{4}$ does not dissociate to yield exactly one free hydrogen ion. This value varies from -0.1 to +0.15 in preliminary calculations that do not account for the changes in the activity coefficient due to the salt background.

${ }^{3}$ The concentration of the background salt solution is 0.125 molal.

${ }^{4}$ Temperature is $50^{\circ} \mathrm{C}$.

AFM images show that the dissolution rates in $\mathrm{HCl}$ and oxalic acid solutions are a function of grain orientation. The mechanism of corrosion for $\mathrm{HNO}_{3}$ is mild intergranular attack. This may be caused by nitrate depletion from the crevice-like geometry. The morphology of the stepped surfaces in $\mathrm{H}_{2} \mathrm{SO}_{4}$ suggests that sulfates may interact with the Alloy 22 surface by site-specific interactions at surface steps.

This work clearly shows that in a crevice environment, nitrate effectively inhibits localized corrosion by raising the OCP and passivating the surface. This can occur through coupled partial reactions such as:

$$
\mathrm{Cr} \rightarrow \mathrm{Cr}^{3+}+3 e^{-}
$$

and

$$
3 e^{-}+\mathrm{NO}_{3}^{-} \rightarrow \mathrm{NO}_{2}(\mathrm{~g})+1 / 2 \mathrm{O}_{2}(\mathrm{~g})
$$

Their net effect is to oxidize the chromium, ultimately converting it to $\mathrm{Cr}_{2} \mathrm{O}_{3}$. There are many species of nitrogen of lower oxidation number that could be formed as potential products (e.g., $\mathrm{NO}_{2}^{-}, \mathrm{N}_{2}, \mathrm{~N}_{2} \mathrm{O}, \mathrm{NO}$, and $\mathrm{NO}_{2}$ ), thus leading to many possible reactions involving nitrate as an oxidant. At this time, it is not possible to say if the increased stabilization is due to the formation of a thicker passivating film or to a change in the structure or defect density within the film. However, in milder conditions $(\mathrm{pH} \sim 3)$, the 
passive oxide was shown to thin slightly as the potential increased within the passive region; thus, it is more likely that nitrate (which increases the OCP) acts to improve the quality of the oxide film rather than thickening it. An increased nitrate/chloride ratio has two positive effects that reduce the likelihood of crevice corrosion: it moves the breakdown potential to higher potentials $\sim E_{\text {trans }} \propto{\frac{\left[\mathrm{NO}_{3}\right]}{[\mathrm{Cl}]}}^{0.3}$ (in the range tested); and it exponentially reduces corrosive currents before transpassive dissolution. The inhibitory effects of nitrate solutions support the localized corrosion model, in that it describes Alloy 22 corrosion in terms of nitrate/chloride ratio as shown in Equations 5-7. However, the details differ. In particular, the interpretation that an increased $E_{\text {corr }}$ corresponds to a more corrosion resistant oxide film is not captured by the localized corrosion model, where higher $E_{\text {corr }}$ without a concomitant rise in the $E_{\text {rcrev }}$ increases the likelihood of crevice corrosion.

To get a sense of how the localized corrosion model described by Equations 5-7 can be compared with the results of the titration model, we plot one case with a $\mathrm{NO}_{3} / \mathrm{Cl}$ ratio of 0.5 , a temperature of $60^{\circ} \mathrm{C}$, and $1 \mathrm{~m} \mathrm{NaCl}$ initial solution (Figure 24). Comparing $E_{\text {corr }}$ from the model (solid black, Equation 5) with the measured value (dotted grey) shows that the model result is significantly higher at all acid concentrations, which is a conservative stance. $E_{\text {rcrev }}$ (blue, Equations 6-7) is not monotonic in acid concentration because the $\mathrm{NO}_{3} / \mathrm{Cl}$ ratio is constant, which means the $\mathrm{NO}_{3}$ concentration is increasing as the acid is increased. The difference between $E_{\text {corr }}$ and $E_{\text {rcrev }}$ is plotted in red. Where this curve is positive, crevice corrosion can initiate and the model corrosion rate is set to $127 \mu \mathrm{m} /$ year. By comparison, the largest measured corrosion rate (from the titration experiments) is $1.3 \mu \mathrm{m} /$ year. This occurs at the lowest $\mathrm{pH}$ value (green trace).

The difficulty with this comparison is that the model is based on bulk solution values and unknown crevice solutions, whereas the titration experiments measure corrosion rates in bulk solutions that mimic crevice solutions. The YMP localized corrosion model suggests that a bulk solution with a $-\log \left[\mathrm{H}^{+}\right]$value of $\sim 4.5$ leads to a $\log \left[\mathrm{H}^{+}\right]$value of less than -0.6 within the crevice (because this is where the oxide film breaks down). This implies that a crevice must be able to sustain a concentration gradient where the internal and external solutions differ by 5 orders in magnitude. Moreover, for this $\mathrm{NO}_{3} / \mathrm{Cl}$ ratio and temperature, there are no transient regions where high currents develop before transpassive dissolution. Thus, if the $\mathrm{NO}_{3} / \mathrm{Cl}$ ratio of 0.5 is sustained within the crevice, it is unclear how crevice corrosion would initiate to drive the internal chemistry to the high acid concentrations required to break down the oxide. This reasoning suggests that the model is overly conservative and can be improved by considering sustainable concentration gradients in crevice geometries. 


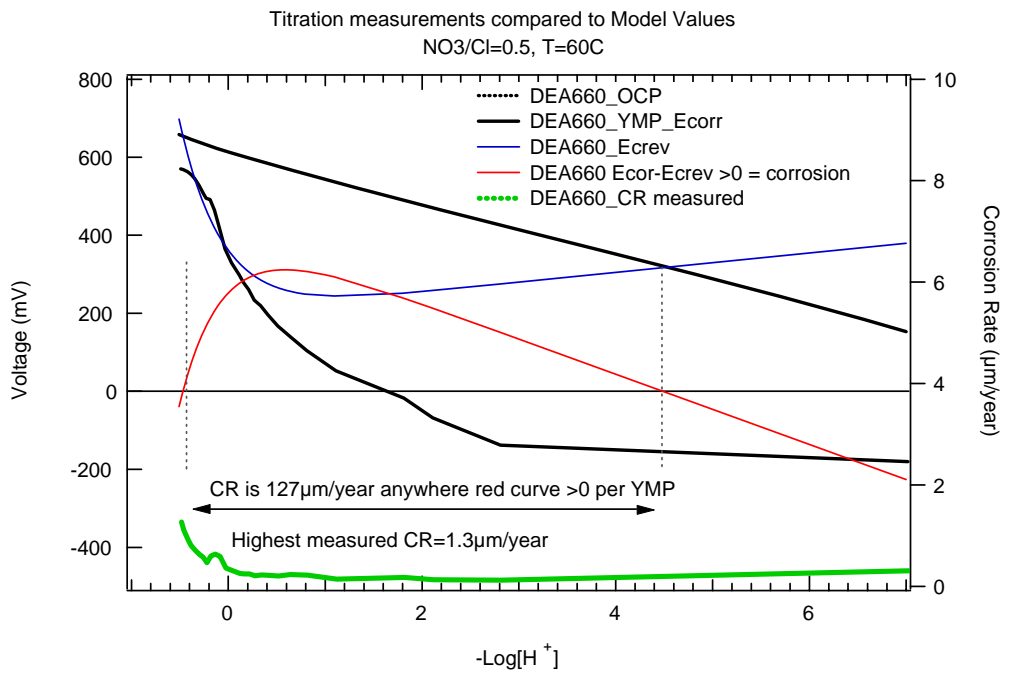

Figure 24. Titration measurements compared with the localized corrosion model for $\mathrm{NO}_{3} / \mathrm{Cl}$ of $0.5, T=60^{\circ} \mathrm{C}$, and $1 \mathrm{~m}$ initial $\mathrm{NaCl}$ solution.

The inhibitory effects of nitrate are important because they indicate that nitrate present in evaporating seepage water will mitigate any localized corrosion. Even at low $\mathrm{NO}_{3} / \mathrm{Cl}$ ratios of 0.05 at 60 and $90^{\circ} \mathrm{C}$, our titration experiments indicate that initial corrosion sites will be repassivated. In addition, at $\mathrm{NO}_{3} / \mathrm{Cl} \geq 0.2$, nitrate will effectively stabilize the passive film. However, because nitrate is depleted through reactions in which it acts to oxidize zero-valent metal, the sustainability of such reactions within a crevice will depend upon effective coupling with the environment (in order to replenish the nitrate). Nitrate is the most effective inhibitor found in evaporating seepage water. Although sulfate may also be present, this study shows that it does not stabilize the passive film to the same extent as nitrate.

\section{Acknowledgments}

This work was performed under the auspices of the U.S. Department of Energy by the University of California, Lawrence Livermore National Laboratory under Contract No. W-7405-Eng-48. 


\section{References}

\subsection{Documents Cited}

BSC (Bechtel SAIC Company), 2004a. Waste Package and Drip Shield Corrosion, in Yucca Mountain Repository Safety Analysis Report DOE/RW-XXX cr_sar_234.doc 2.3.6-36 Rev.00, Draft A. Washington, D.C.: U.S. Department of Energy, Office of Civilian Radioactive Waste Management.

BSC (Bechtel SAIC Company), 2004b. General Corrosion and Localized Corrosion of Waste Package Outer Barrier, ANL-EBS-MD-000003 REV 02. Las Vegas, Nevada: Bechtel SAIC Company. ACC: DOC.20041004.0001.

BSC (Bechtel SAIC Company), 2004c. Appendix N: Waste package and drip shield materials: Passive film characteristics, growth, and stability (Response to container life and source term 1.08 and container life and source term 1.09 CLST) REV 1 (C). Las Vegas, Nevada: Bechtel SAIC Company. ACC: MOL.20040923.0106.

Carroll, S., Alai, M., Craig, L., Gdowski, G., Hailey, P., Nguyen, Q. A., Rard, J., Staggs, K., Sutton, M., and Wolery, T. (2005) Chemical Environment at Waste Package Surfaces in a High-Level Radioactive Waste Repository. UCRL-TR-207919, Lawrence Livermore National Laboratory, Livermore, CA.

Farmer, J. C., McCright, R. D., Gdowski, G. E., Wang, F., Summers, T. S. E., P., Bedrossian, Horn, J. M., Lian, T., Estill, J. C. (2000) A. Lingenfelter and W. Halsey, Transportation, Storage, and Disposal of Radioactive Materials 2000, PVP-ASME, v. 408, p. 53, New York, NY.

Hayes, J. 2004a. Oxide Characterization. Scientific Notebook SN-LLNL-SCI-465-V4. ACC: MOL.20050414.0208.

Hayes, J. 2004b. Oxide Characterization. Scientific Notebook SN-LLNL-SCI-465-V5. ACC: MOL.20050414.0202.

LLNL (Lawrence Livermore National Laboratory) 2004a. Acceptance Report for Scientific Investigations, for Charles Evans \& Associates, X-Ray Photoelectron Spectroscopy (XPS) Surface Analysis Report. EAG Number: C04J4575. PO BA004609, REL 52456. ACC: MOL.20041015.0104.

LLNL (Lawrence Livermore National Laboratory) 2004b. Acceptance Report for Scientific Investigations, for Charles Evans \& Associates, Auger Electron Spectroscopy (AES) Surface Analysis Report. EAG Number: C04J4575. PO BA004609, REL 52456. ACC: MOL.20041101.0419.

LLNL (Lawrence Livermore National Laboratory) 2004c. Acceptance Report for Scientific Investigations, for Charles Evans \& Associates, X-Ray Photoelectron Spectroscopy (XPS) Surface Analysis Report. EAG Number: C04J0890. PO BA004609, REL 46868. ACC: MOL.20041007.0076.

Wong, L., Estill, J. C., Fix, D. V., Rebak, R. B. (2003a) General and localized corrosion behavior of titanium grades 7, 16 and 12 in simulated concentrated ground waters. Submitted to 2003 American Society of Mechanical Engineers Pressure Vessels and Piping Conference, Cleveland, OH, July 20 24, 2003. Preprint UCRL-JC-152097, Lawrence Livermore National Laboratory, Livermore, CA.

American Society of Mechanical Engineers Pressure Vessels and Piping Conference.

Wong, L. L., Fix, D. V., Estill, J. C., McCright, R. D., Rebak, R. B. (2003b) Characterization of the corrosion behavior of Alloy 22 after five years immersion in multi-ionic solutions. Scientific Basis for Nuclear Waste Management XXVI, Symposium held December 2-5, 2002, Boston, Massachusetts. Finch, R.J. and Bullen, D.B., eds. 757, 735-741. Warrendale, Pennsylvania: Materials Research Society.

Wong, L. L., Lian, T., Fix, D. V., Sutton M., Rebak, R. B. (2003c) Surface analysis of Alloy 22 coupons exposed for five years to concentrated ground waters. Submitted to NACE International, Corrosion Conference. Las Vegas, Nevada: Bechtel SAIC Company. ACC: MOL.20050103.0034.

$\mathrm{Xu}, \mathrm{Y}$. and Pickering, H. W. (1993) "The Initial Potential and Current Distributions of the Crevice Corrosion Process,” J. Electrochemical Society, Vol. 140, No. 3, pp. 658-668. 


\subsection{Codes, Standards, and Regulations}

ASTM G 59-97. 1998. Standard Test Method for Conducting Potentiodynamic Polarization Resistance Measurements. West Conshohocken, Pennsylvania: American Society for Testing and Materials. TIC: 249897.

ASTM G 102-89 (Reapproved 1999) 1989. Standard Practice for Calculation of Corrosion Rates and Related Information from Electrochemical Measurements. West Conshohocken, Pennsylvania: American Society for Testing and Materials. TIC: 249897.

ASTM G1-90 (Reapproved 1999) Standard Practice for Preparing, Cleaning, and Evaluating Corrosion Test Specimens. West Conshohocken, Pennsylvania: American Society for Testing and Materials. TIC 238771

\subsection{Data, Listed by Data Tracking Number}

LL030412512251.057 LTCTF Corrosion Rate Calculations for Five-Year Exposed Alloy C22 Specimens Cleaned Under TIP-CM-51. Submittal date: 5/28/03.

LL040502512251.099 Weight Loss Measurements and Weight Loss Corrosion Rates from Alloy 22 Foil Specimens. Submittal date: 04/20/2004.

LL040907112251.122 Weight Loss Measurements and Weight Loss Corrosion Rates from Alloy 22 Foil Specimens. Submittal date: 10/20/2004. 